\title{
Identification and Characterization of 2'-Deoxyuridine from the Supernatant of Conidial Suspensions of Rice Blast Fungus as an Infection-Promoting Factor in Rice Plants
}

\author{
Sugihiro Ando, ${ }^{1}$ Yuko Sato, ${ }^{1}$ Hideyuki Shigemori, ${ }^{2}$ Takafumi Shimizu, ${ }^{3}$ Kazunori Okada, ${ }^{3}$ \\ Hisakazu Yamane, ${ }^{3}$ Yusuke Jikumaru, ${ }^{4}$ Yuji Kamiya, ${ }^{4}$ Kosumi Yamada, ${ }^{2}$ Chiharu Akimoto-Tomiyama, ${ }^{1}$ \\ Shigeru Tanabe, ${ }^{1}$ Yoko Nishizawa, ${ }^{1}$ and Eiichi Minami ${ }^{1}$ \\ ${ }^{1}$ Division of Plant Sciences, National Institute of Agrobiological Sciences, 2-1-2 Kannondai, Tsukuba, Ibaraki 305-8602, Japan; \\ ${ }^{2}$ Graduate School of Life and Environmental Sciences, University of Tsukuba, 1-1-1 Tennodai, Tsukuba, Ibaraki 305-8572, \\ Japan; ${ }^{3}$ Biotechnology Research Center, The University of Tokyo, 1-1-1 Yayoi, Bunkyo-ku, Tokyo 113-8657, Japan; ${ }^{4}$ RIKEN, \\ Plant Science Center, Tsurumi-ku, Yokohama 230-0045, Japan
}

Submitted 28 July 2010. Accepted 15 December 2010.

\begin{abstract}
We previously detected infection-promoting activity in the supernatant of the conidial suspension (SCS) of the rice blast fungus. In the present study, a molecule carrying the activity was purified and identified as 2'-deoxyuridine (dU). The infection-promoting activity of dU was strictly dependent on its chemical structure and displayed characteristics consistent with those of the SCS. Notably, the activity of dU was exclusively detected during interactions between rice and virulent isolates of the fungus, the number of susceptible lesions in leaf blades was increased by $\mathrm{dU}$, and nonhost resistance in rice plants was not affected by treatment with dU. In addition, the expression of pathogensis-related genes, accumulation of $\mathrm{H}_{2} \mathrm{O}_{2}$, and production of phytoalexins in rice in response to inoculation with virulent fungal isolates was not suppressed by $\mathrm{dU}$. The infection-promoting activity of dU was not accompanied by elevated levels of endogenous abscissic acid, which is known to modify plant-pathogen interactions, and was not detected in interactions between oat plants and a virulent oat blast fungus isolate. Taken together, these results demonstrate that $\mathrm{dU}$ is a novel infection-promoting factor that acts specifically during compatible interactions between rice plants and rice blast fungus in a mode distinct from that of toxins and suppressors.
\end{abstract}

When plants are infected with pathogens, a set of defense responses is typically induced, including the production of reactive oxygen species, changes in host cell walls, accumulation of phytoalexins, expression of pathogenesis-related proteins, and the localized death of host cells; this defense reaction

Current address for S. Ando: Graduate School of Agricultural Science, Tohoku University, 1-1 Amamiya-machi, Tsutsumidori, Aoba-ku, Sendai, Miyagi, 981-8555, Japan.

Corresponding author: Eiichi Minami; E-mail: eiminami@affrc.go.jp

* The $\boldsymbol{e}$-Xtra logo stands for "electronic extra" and indicates that a supplementary table is published online.

This article is in the public domain and not copyrightable. It may be freely reprinted with customary crediting of the source. The American Phytopathological Society, 2011. is typically referred to as the hypersensitive response (Dixon and Lamb 1990; Ferreira et al. 2006). However, a number of classes of fungal pathogens produce both nonselective and host-selective toxins (HST) and suppressors to avoid and also utilize host defense responses (Shiraishi et al. 1997; Wolpert et al. 2002). To date, HST have only been found in four necrotrophic fungal genera of phytopathogens, namely, Alternaria, Cochliobolus, Pyrenophora, and Stagonospora (Friesen et al. 2008).

HST cause necrosis, which allows fungi to proliferate by consuming released host nutrients, and also compromises resistance of susceptible host plants to nonvirulent fungi and nonhost pathogens. The target receptors and high-affinity binding proteins for several HST have been identified in a number of host plants (Wolpert et al. 2002). For example, Cochliobolus heterostrophus (Bipolaris maydis), the causal agent of Southern corn leaf blight, produces T-toxin, an HST that binds to a $13-\mathrm{kDa}$ mitochondrial protein in maize, resulting in impaired mitochondrial function (Dewey et al. 1988).

In addition to toxins, fungal pathogens also synthesize factors, termed suppressors, that specifically inhibit plant host defense responses without inducing visible damage. Suppressors induce local susceptibility to nonhost pathogens and act with specificity at the levels of race cultivar, host species, and genus (Shiraishi et al. 1997). A fungal pathogen of pea, Mycosphaerella pinodes, was reported to produce a suppressor that reduces the level of the pea phytoalexin pisatin (Oku et al. 1977). Subsequent attempts to purify the suppressor revealed the inhibitory activity was the result of two mucin-type glycopepetides, supprescins A and B (Shiraishi et al. 1992), in the elicitor fraction of the pathogen. As the suppressors alone were able to delay the activation of defense-related genes in pea (Wada et al. 1994), the suppressor activity does not appear to require the presence of viable pathogens. Similar results have been demonstrated for suppressors from Phytophothora infestans, the causal pathogen of potato late blight disease (Doke 1975), and from P. megasperma, the causal pathogen of soybean stem blight disease (Ziegler and Pontzen 1982). These observations indicate that the primary targets of suppressors, as well as HST, are located within host cells.

Rice blast fungus (Magnaporthe oryzae, Oryzae isolate) is a hemibiotrophic fungus that causes blast disease in rice, which 
accounts for major losses in the global yield of rice (Talbot 2003). M. oryzae begins its life cycle when a conidium attaches to the surface of a rice leaf, germinates, and forms a specialized infection cell, known as the appressorium (Gilbert et al. 1996; Lee and Dean 1993; Xiao et al. 1994). The mature appressorium accumulates glycerol, which generates cellular turgor pressure that results in the emergence of the penetration peg (de Jong et al. 1997; Howard et al. 1991), a slender hypha that effectively ruptures the plant cuticle and underlying cell wall to initiate invasion. A branched infectious hypha then fills the first encountered plant cell and, subsequently, extends into proximate host cells, intercellular spaces, or both (Heath et al. 1990, 1992). Eventually, a lesion develops at the infection site, which yields mycelia that sporulate and release more conidia to reinitiate the infection cycle (Tucker and Talbot 2001). The interaction between the rice plant and rice blast fungus represents a gene-for-gene system (Liu et al. 2010).

During the interaction between rice and rice blast fungus, a number of fungal factors that stimulate infection have been characterized, including several nonspecific phytotoxins (Iwasaki et al. 1969, 1972; Nukina et al. 1981; Umetsu et al. 1972). However, the roles of these phytotoxins in fungal pathogenicity are not clear; for example, tenuazonic acid, a phytotoxin of rice blast fungi, is also produced by a nonpathogenic fungus of rice plants, Alternaria alternata, and acts as an inhibitor of photosystem II in nonrice plants (Chen et al. 2007).
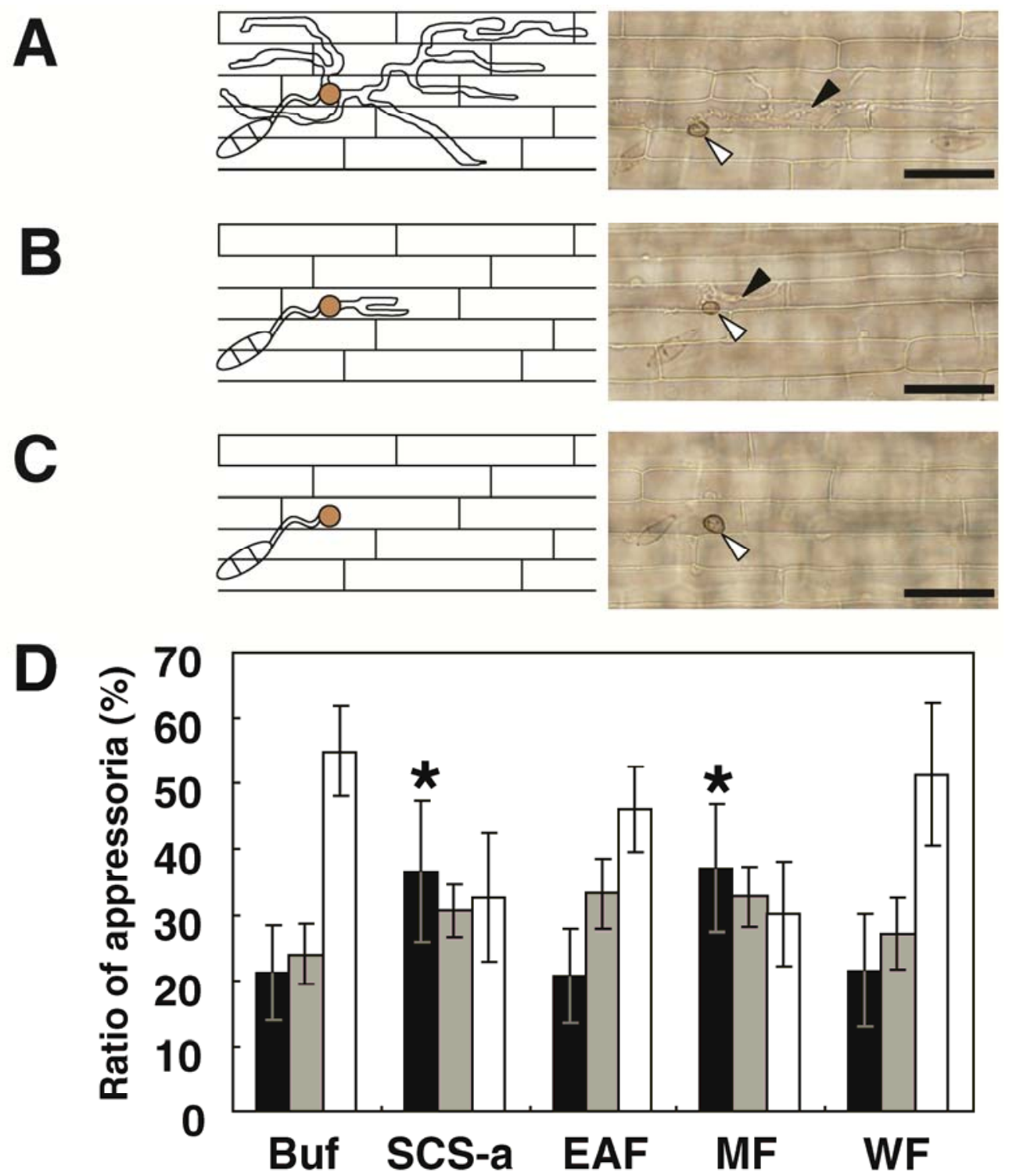

\section{- Infected $\square$ One cell infected $\square$ Uninfected}

Fig. 1. Detection of infection-promoting activity in the methanol-soluble fraction of a supernatant of the conidial suspension (SCS) from rice blast fungus. Representative photographs and schematic patterns of infectious hyphae from appressorium classified as A, infected, B, one cell infected, and $\mathbf{C}$, uninfected. Open and filled arrowheads indicate appressorium and infectious hyphae, respectively. Bars indicate $40 \mu \mathrm{m}$. D, Leaf-sheath assay using SCS after extraction with organic solvents. Washed conidia of Ina86-137 were suspended in $1 \mathrm{mM}$ MES-NaOH (pH 5.7, Buf) or the identical buffer containing SCS-a and the ethyl acetate-soluble (EAF), methanol-soluble (MF), and water-soluble fractions (WF), which were adjusted to a concentration equivalent to SCS-a, were used in a leaf-sheath assay with rice cv. Nipponbare (Pia). Bars represent the means ( \pm standard deviation) of five to six individual leaf sheaths. Asterisks denote significant differences in the ratio of infected appressoria compared with the buffer control (Buf, $1 \mathrm{mM}$ MES-NaOH, $\mathrm{pH} 5.7)(\mathrm{Dunnett}$ 's test, $P<0.05)$. 
A pathogenesis-related activity was found in the supernatant of conidia suspension after incubation for up to $24 \mathrm{~h}$ that allows conidial germination (spore germination fluids [SGF]). A. alternata, a nonhost pathogen of rice, can form lesions on leaves of rice and other graminaceous plants that are natural hosts of rice blast fungus, such as barley and perennial ryegrass, in the presence of SGF (Fujita et al. 1994), whereas the sole application of SGF to plants does not induce any visible changes (Arase et al. 1990; Fijita et al. 1994, 1995). Furthermore, SGF of rice blast fungus displays protoplast-disrupting activity that is specific to rice but not to nonhost plants (Rathour et al. 2002). However, the chemical structures of the factors in SGF that are responsible for these activities are unknown.

We previously reported heat-labile catalase activity in the supernatant obtained by centrifugation and filtration of freshly prepared conidial suspension (supernatant of the conidial suspension $[\mathrm{SCS}]$ ) of various isolates of rice blast fungi (Tanabe et al. 2008). The catalase also exhibited infection-promoting activity in both compatible and incompatible interactions, likely due to quenching of hydrogen peroxide, which is nonspecifically toxic to rice blast fungi (Tanabe et al. 2009). We further analyzed the SCS for factors involved in fungal patho- genicity and found that heat-treated SCS lacking catalase activity still exhibited infection-promoting activity that was specific to compatible interactions between rice plants and rice blast fungus. The application of heat-treated SCS increased the ratio of susceptible lesions in leaf blades but did not induce local susceptibility in rice plants to nonhost pathogens. Similar activities were detected in SCS from a variety of Japanese rice blast fungal isolates (Ando et al. 2009).

In this study, we identified the molecule responsible for the infection-promoting activity in SCS of rice blast fungus as 2'deoxyuridine (dU). The characteristics of the infection-promoting activity of dU were consistent with those of the activities found in SCS. We demonstrate that this novel factor displays activity that is distinct from previously characterized fungal toxins and suppressors.

\section{RESULTS}

\section{Purification of the infection-promoting factor} from SCS of rice blast fungus.

Our previous results indicated that SCS adjusted to the equivalent of $40 \mu \mathrm{g}$ glucose per milliliter exhibited the highest
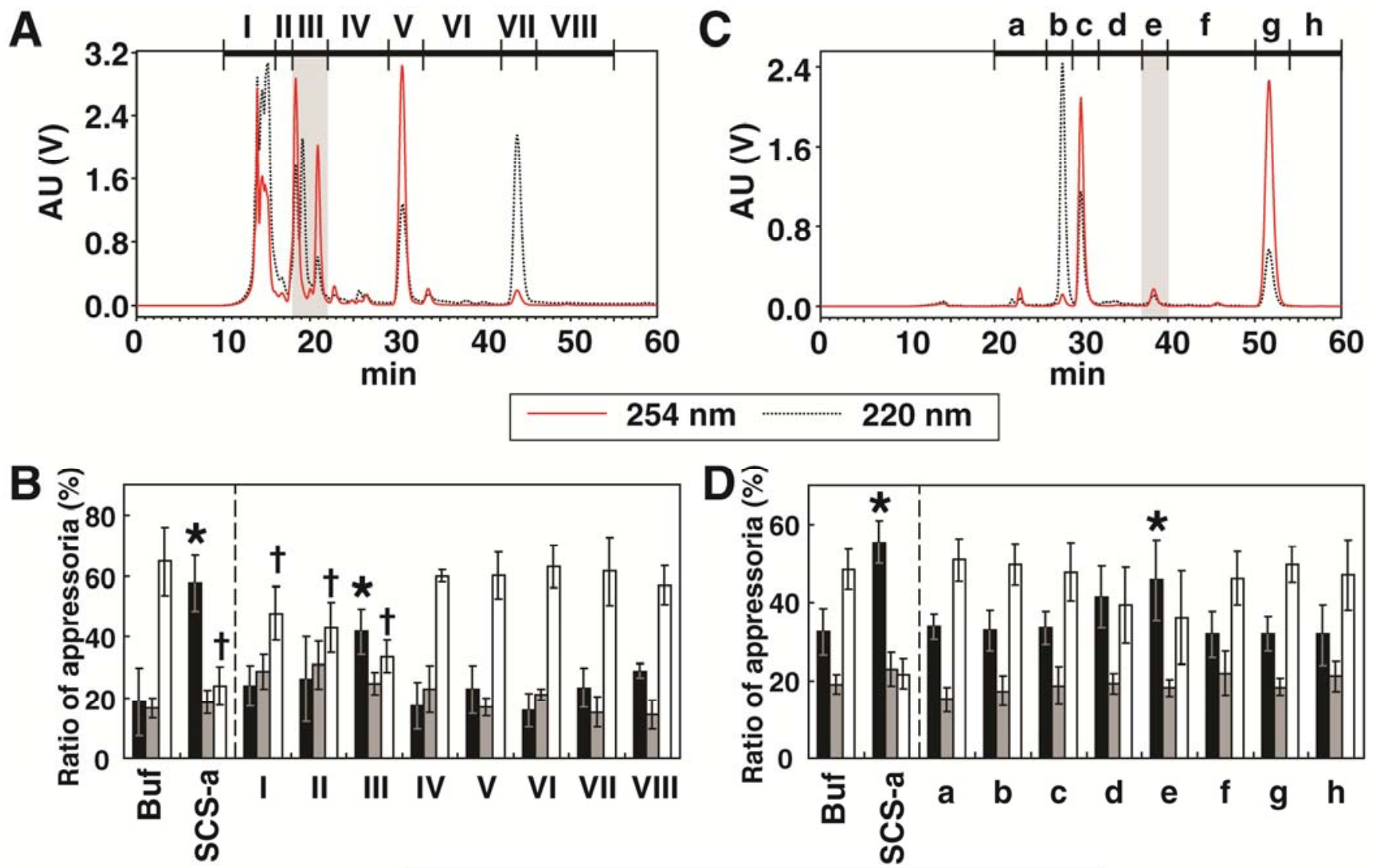

\section{Infected $\square$ One cell infected $\square$ Uninfected}

Fig. 2. High-performance liquid chromatography (HPLC) fractionation of the methanol-soluble fraction of a rice blast fungus supernatant of the conidial suspension (SCS) and measurement of infection-promoting activity in the leaf-sheath assay. A, Separation of the methanol-soluble materials of SCS by reversephase HPLC column chromatography with mobile phase A. Ten minutes after injection, 45 1-ml fractions were collected and combined to form fractions I to VIII. Fractions I, II, and III (shaded) correspond to the combined fractions with retention times of 10 to 16,16 to 18 , and 18 to 22 min, respectively. B, Leafsheath assay for the infection-promoting activity of the fractions prepared in A, using Ina86-137 and rice cv. Nipponbare (Pia). Each fraction was used at a concentration equivalent to SCS-a. Bars represent the means ( \pm standard deviation [SD]) of five to seven individual leaf sheaths. Asterisks and daggers denote significant differences in the ratio of infected and uninfected appressoria, respectively, compared with the buffer control (Buf, $1 \mathrm{mM} \mathrm{MES}-\mathrm{NaOH}$, $\mathrm{mH}$ 5.7) (Dunnett's test, $P<0.05$ ). C, Separation of fraction III as shown in A by reverse-phase HPLC column chromatography with mobile phase B. Twenty minutes after injection, $401-\mathrm{ml}$ fractions were collected and combined to form fractions a to h. Fraction e (retention time, 37 to 40 min) is shaded. D, Leafsheath assay for the infection-promoting activity of the fractions prepared in C, using Ina86-137 and rice cv. Nipponbare (Pia). Each fraction was used at a concentration equivalent to SCS-a. Bars represent the means $( \pm \mathrm{SD})$ of five to six individual leaf sheaths. Asterisks denote significant differences compared with the buffer control (Buf, $1 \mathrm{mM}$ MES-NaOH, pH 5.7) (Dunnett's test, $P<0.05$ ). 
infection-promoting activity (Ando et al. 2009); therefore, we used adjusted SCS (hereafter referred to as SCS-a) as a positive control in this study. To purify the factor responsible for the heat-stable infection-promoting activity, we first performed successive extractions of Ina86-137 SCS with ethyl acetate, methanol, and water. Washed conidia of Ina86-137 were suspended in each of three obtained fractions and their infectivities were tested in the leaf sheaths of rice cv. Nipponbare (Pia); representative "infected," "one cell-infected", and "uninfected" appressoria are shown in Figure 1A, B, and C, respectively. The infection-promoting activity in SCS was exclusively recovered in the methanol-extracted fraction (MF), while the ethyl acetate- and water-extracted fractions (EAF and WF, respectively) showed no significant activities (Fig. 1D).

The MF was subsequently analyzed by reverse-phase column chromatography using Inertsil ODS-3 with 25\% methanol (high-performance liquid chromatography [HPLC], step 1) and was separated into eight fractions (Fig. 2A, I to VIII), which were then applied to the leaf-sheath assay. Although fractions I and II slightly but significantly stimulated infection by reducing the ratio of uninfected appressoria (Fig. 2B), the major stimulatory activity was recovered in fraction III, indicating that SCS includes more than one infection-promoting factor. We further separated fraction III by HPLC on Inertsil ODS-3 with $10 \%$ methanol (HPLC, step 2), and the resultant eight fractions (Fig. 2C, a to $\mathrm{h}$ ) were subjected to the leaf-sheath assay as before. Notably, the activity of fraction e was significantly higher than activities observed in the other seven fractions (Fig. 2D). Table 1 summarizes the yields of the infectionpromoting factor in each fraction of the two purification steps, as determined by dry weight.

Due to the high activity of fraction e, which had a dry weight of $0.96 \mathrm{mg}$ ( $2.52 \%$ of fraction III), we analyzed the chemical structure of the eluted factor by nuclear magnetic resonance $\left({ }^{1} \mathrm{H}-\mathrm{NMR}\right)$. The ${ }^{1} \mathrm{H}-\mathrm{NMR}\left(500 \mathrm{MHz}, \mathrm{D}_{2} \mathrm{O}\right)$ spectrum of fraction e showed $\delta 7.79(1 \mathrm{H}, \mathrm{d}, J=8.2 \mathrm{~Hz}, \mathrm{H}-6), 6.22(1 \mathrm{H}, \mathrm{t}$, H-1'), 5.83 (1H, d, $J=8.2 \mathrm{~Hz}, \mathrm{H}-5), 4.40$ (1H, m, H-4'), 3.99 (1H, m, H-3'), 3.68 (2H, m, H-5'), and 2.34 (2H, m, H-2'); fast atom bombardment mass spectroscopy (FABMS) (pos.) $\mathrm{m} / z \quad 251(\mathrm{M}+\mathrm{Na})^{+}$, and $229(\mathrm{M}+\mathrm{H})^{+}$; and high-resolution FABMS $m / z 251.06439(\mathrm{M}+\mathrm{Na})^{+}$, indicating a molecular formula of $\mathrm{C}_{9} \mathrm{H}_{12} \mathrm{~N}_{2} \mathrm{O}_{5} \mathrm{Na}$ and a molecular weight of 251.06404, which are indistinguishable from those of dU. High-resolution mass spectrometry analysis confirmed that fraction e included dU (data not shown).

As dU is a ubiquitous compound in living organisms, we examined the possibility that it was supplied from an extract of the oatmeal agar medium (EOM) used to culture the rice blast fungus. We estimated the content of dU in SCS and EOM (prepared using the identical method as SCS) to be $1.36 \mu \mathrm{M}$ and $23 \mathrm{nM} \mathrm{g}^{-1} \mathrm{dw}$ (dry weight) of the MF, respectively, by HPLC.
As these values were equivalent to 110 and $1.87 \mathrm{nM} \mathrm{dU}$, respectively, these results suggest that the dU present in fraction e predominantly originated from SCS.

\section{Confirmation and characterization of the infection-promoting activity of $\mathrm{dU}$.}

The fractionation and ${ }^{1} \mathrm{H}-\mathrm{NMR}$ results indicated that $\mathrm{dU}$ was the prominent molecule responsible for the infection-promoting activity of SCS. We next tested the activity of various concentrations of chemically synthesized dU and found that $\geq 100$ $\mathrm{nM}$ synthetic $\mathrm{dU}$ showed infection-promoting activity comparable to SCS-a (Fig. 3A). When the increase in fungal biomass in rice leaf sheaths was estimated by measuring the amount of $28 \mathrm{~S}$ rDNA at 48 and $72 \mathrm{~h}$ postinoculation (hpi), the effect of 1 $\mu \mathrm{M}$ synthetic $\mathrm{dU}$ was first evident at $72 \mathrm{hpi}$ (Fig. 3B). This delayed increase in fungal biomass relative to the visual levels of infection suggested that the growth of hyphae was not accompanied by the duplication of nuclear DNA at $48 \mathrm{hpi}$. In contrast to the stimulation of hyphal growth in planta, $10 \mathrm{nM}$ to $10 \mu \mathrm{M}$ $\mathrm{dU}$ did not show any effects on in vitro growth of the rice blast fungus (Fig. 4).

To determine whether the characteristics of the infectionpromoting activity in SCS were attributable to $\mathrm{dU}$, we first examined the dependency of the effects of $\mathrm{dU}$ on compatibility. As shown in Figure 3A, dU at $1 \mu \mathrm{M}$ displayed infectionpromoting activity in rice cv. Nipponbare (Pia) inoculated with a virulent isolate, Ina86-137, but had no effect on the incompatible interaction between rice cv. Nipponbare $(P i k)$ and Ina86-137 (AvrPik) (Fig. 5A). Similarly, the identical concentration of dU promoted P91-15B (AvrPia) infection of the susceptible rice cv. Nipponbare $(+/+)$ (Fig. 5B) but not that of the resistant rice cv. Nipponbare (Pia) (Fig. 5C). Therefore, the effects of $\mathrm{dU}$ were restricted to compatible interactions and were independent of fungal isolates and blast-resistance genes of rice. Furthermore, the infection of rice leaf sheaths by Avena isolate 4-1 was not stimulated by dU (Fig. 5D), indicating that $\mathrm{dU}$ does not induce local susceptibility in rice to nonhost pathogens.

We next examined the effects of $\mathrm{dU}$ on lesion formation in rice leaf blades. Inoculation with conidia of Ina86-137 suspended in $1 \mu \mathrm{M}$ dU increased the ratio of lesions in the leaf blades of susceptible rice cv. Nipponbare (Pia) (9.3\%) compared with that of the control experiment $(5.5 \%)$. In addition, it was found that $10 \mu \mathrm{M}$ dU was required to exhibit an effect on lesion formation in leaf blades comparable to SCS-a (15.2 and $13.6 \%$, respectively) (Fig. 6), whereas $0.1 \mu \mathrm{M}$ dU showed saturated activity in the leaf-sheath assay (Fig. 3). The requirement for higher concentrations of $\mathrm{dU}$ on leaf blades relative to leaf sheaths to achieve an infection-promoting activity comparable to SCS-a may be due to differences in the tissues examined or one or more unknown factors other than dU present in SCS.

Table 1. Purification steps and yields of the infection-promoting factor

\begin{tabular}{|c|c|c|c|c|c|c|c|c|c|}
\hline \multicolumn{3}{|c|}{ Step 1} & \multicolumn{3}{|c|}{ HPLC $^{\text {a }}$ step 1} & \multicolumn{4}{|c|}{ HPLC step 2} \\
\hline SCS (mg) & Fraction & $\% \pm \mathrm{SD}$ & Methanol fraction (mg) & Fraction & $\%$ & III (mg) & Fraction & $\%$ & mg \\
\hline \multirow[t]{9}{*}{$1,910.7$} & Ethyl acetate & $4.65 \pm 0.43$ & 762.0 & I & 65.8 & 38.1 & $\mathrm{a}$ & 9.32 & \\
\hline & Methanol $^{\mathrm{b}}$ & $52.50 \pm 3.55$ & & II & 5.27 & & $\mathrm{~b}$ & 37.8 & \\
\hline & Aqueous & $20.40 \pm 3.07$ & & III & 5.22 & & $\mathrm{c}$ & 13.3 & \\
\hline & Insoluble material & $22.50 \pm 4.97$ & & IV & 1.86 & & d & 9.53 & \\
\hline & & & & $\mathrm{V}$ & 2.18 & & $\mathrm{e}$ & 2.52 & 0.96 \\
\hline & & & & VI & 1.18 & & $\mathrm{f}$ & 2.65 & \\
\hline & & & & VII & 0.64 & & $\mathrm{~g}$ & 9.58 & \\
\hline & & & & VIII & 0.60 & & $\mathrm{~h}$ & 1.10 & \\
\hline & Recovery (\%) & 99.6 & & Recovery (\%) & 82.8 & & Recovery (\%) & 85.8 & \\
\hline
\end{tabular}

\footnotetext{
${ }^{\text {a }}$ HPLC $=$ high performance liquid chromatography.

${ }^{\mathrm{b}}$ Gray shading indicates fraction-containing activity.
} 
The results for synthetic dU shown in Figures 3, 5, and 6 are consistent with those obtained with SCS; namely, dU promoted infection in compatible interactions, did not compromise resistance to nonhost pathogens, and increased the ratio of susceptible lesions in leaf blades. Taken together, these data suggest that dU was largely responsible for the infection-promoting activity in the SCS of rice blast fungus.

\section{Effects of dU action in oat plants.}

As dU is a common metabolite of both plants and fungal pathogens, we assessed whether dU exhibits similar infectionpromoting activities during pathogenic interactions in plants other than rice. The leaf sheaths of oat $\mathrm{cv}$. Haeibuki were inoculated with a virulent isolate of oat blast fungus, 4-1, and the extent of infection was measured. However, as shown by the ratio of infective appressoria, dU did not exhibit infectionpromoting activity (Fig. 7A). When inoculated with the nonhost pathogen Oryzae isolate Ina86-137, dU did not compromise the nonhost resistance in oat cv. Haeibuki (Fig. 7B). These results indicate that the effects of $\mathrm{dU}$ are specific to interactions between rice and virulent rice blast fungus isolates.

\section{Activity of compounds similar to dU.}

Once incorporated into living cells, $\mathrm{dU}$ is converted into other compounds, such as 2'-deoxyuridine monophosphate (dUMP) or uridine, in the pyrimidine metabolic pathway. As we hypothesized that dU acts inside rice or rice blast fungus cells, compounds metabolically related to dU may exhibit similar infection-promoting activities. To investigate this speculation, we examined the effects of uridine, 2'-deoxycytidine, thymidine, and dUMP in the leaf-sheath assay, and found that none of these compounds had activities similar to dU (Fig. 8A). In addition, fungal biomass was not affected by the treatment of rice plants with either uridine or thymidine (Fig. 8B). These data indicate that the specific chemical structure of dU determines its activity and imply that $\mathrm{dU}$ acts before being incorporated into rice plant or rice blast fungus cells.

\section{Effect of dU on rice plant defense responses.}

We next investigated whether dU suppressed rice defense responses triggered by inoculation with rice blast fungus through the measurement of mRNA levels of pathogenesis related (PR) proteins, $\mathrm{H}_{2} \mathrm{O}_{2}$ formation, and the production of major phytoalexins in the leaf sheaths of rice inoculated with fungus by quantitative reverse transcription-polymerase chain reaction (qRT-PCR), 3',3-diaminobenzidine tetrahydrochloride (DAB) staining, and HPLC-tandem mass spectrometry (MS/MS), respectively.

The expression of four PR genes of rice, germin-like protein (PR15, AK061029), chitinase (PR8, AK100973), PBZ1 (PR10a, AK071613), and thaumatin-like protein (PR5, AK069182), in rice leaf sheaths was investigated (Fig. 9). The examined mRNA levels significantly increased at 48 hpi in response to fungal inoculation, while dU did not suppress the expression of the PR genes in either fungus- or mock-inoculated leaf sheaths of rice. Similarly, we monitored the accumulation of $\mathrm{H}_{2} \mathrm{O}_{2}$ in rice cells in response to fungal inoculation (Fig. 10) and found dU had no significant effects on the pattern of staining (Fig. 10A) or the ratio of DAB-stained cells (Fig. 10B). In addition, the major phytoalexins of rice, momilactones, phytocassanes, and sakuranetin, accumulated in leaf sheaths inoculated with rice blast fungus at $48 \mathrm{hpi}$, but the levels of these phytoalexins were not altered by the presence of dU (Fig. 11). Taken together, these results indicate that the mode of action of $\mathrm{dU}$ is distinct from that of suppressors, which retard the defense responses by host plants (Shiraishi et al. 1997).
Action of $\mathrm{dU}$ is not mediated by abscissic acid (ABA).

Among plant hormones, ABA is reported to suppress the resistance of host plants against pathogens (Asselbergh et al. 2008; Mauch-Mani and Mauch 2005). In rice-rice blast fungus interactions, the application of ABA drastically reduces the resistance of rice to the fungus (Jiang et al. 2010; Koga et al. 2004). Therefore, we investigated whether ABA was involved in the infection-promoting activity of $\mathrm{dU}$ by testing if $\mathrm{ABA}$ had a dose-dependent effect in the leaf-sheath assay. It was confirmed that $20 \mu \mathrm{M}$ ABA exhibited similar effects to dU, i.e., the presence of ABA stimulated infection that was accompanied by a reduced ratio of uninfected appressoria (Fig. 12A). The mRNA level of 9-cis-epoxycarotenoid dioxygenase 3 (OsNCED3, AY838899), a key enzyme in the biosynthesis of ABA (Christmann et al. 2006), was measured in the leaf sheaths by qRT-PCR. Expression of $O s N C E D 3$ was clearly up-

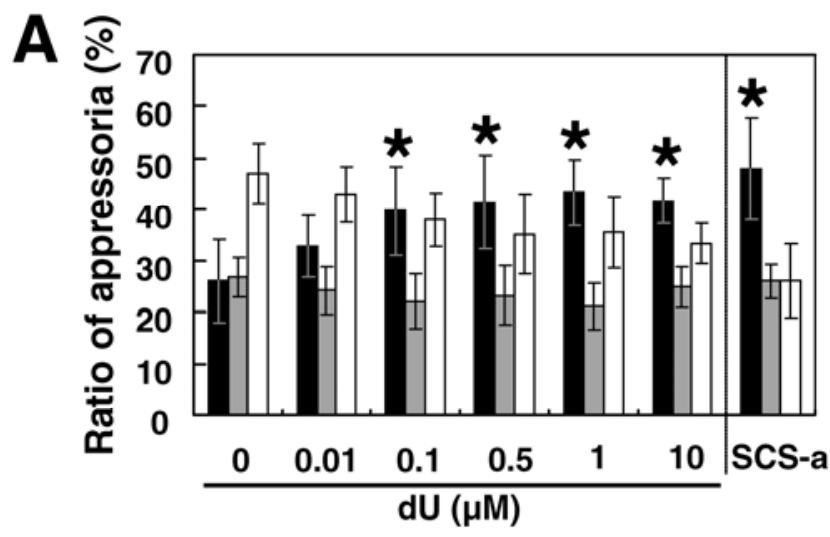

$\square$ Infected $\square$ One cell infected $\square$ Uninfected

B

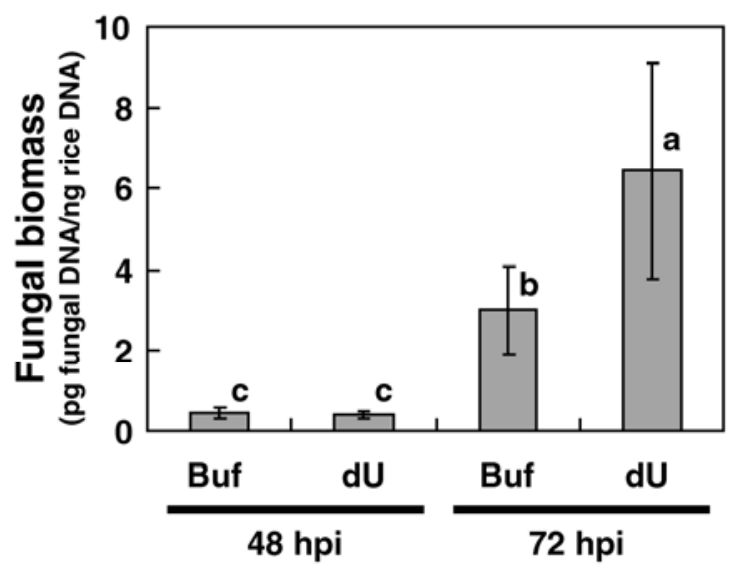

Fig. 3. Effect of synthetic 2'-deoxyuridine (dU) on infection-promoting activity. A, Leaf-sheath assay for the infection-promoting activity of synthetic dU. Washed conidia of Ina86-137 were suspended in 1 mM MES-NaOH (pH 5.7) containing dU or SCS-a and were then inoculated onto leaf sheaths of rice cv. Nipponbare $(\mathrm{Pia})$. Bars represent the means $( \pm$ standard deviation [SD]) of five to eight individual leaf sheaths. Asterisks denote significant differences compared with the buffer control $(\mathrm{dU}=0 \mu \mathrm{M})$ (Dunnett's test, $P<$ $0.05)$. B, Increase in fungal biomass in leaf sheaths in response to the addition of $\mathrm{dU}$ measured by quantitative polymerase chain reaction (qPCR) of fungal DNA. Washed conidia of Ina86-137 were suspended in $1 \mathrm{mM}$ MES$\mathrm{NaOH}(\mathrm{pH}$ 5.7) containing dU and were then inoculated on the leaf sheaths of Nipponbare (Pia). At 48 and $72 \mathrm{~h}$ postinoculation (hpi), the amount of fungal and rice genomic DNA was determined by qPCR based on the fungal $28 \mathrm{~S}$ rDNA and rice $O s W R K Y 76$ DNA detected in the identical extract. Bars represent the mean $( \pm \mathrm{SD})$ of five individual leaf sheaths. The experiment was independently repeated three times and a typical result is shown. Different letters denote significant differences compared with the buffer control (Buf, 1 mM MES-NaOH, pH 5.7) (Tukey-Kramer's test, $P<0.05$ ). 

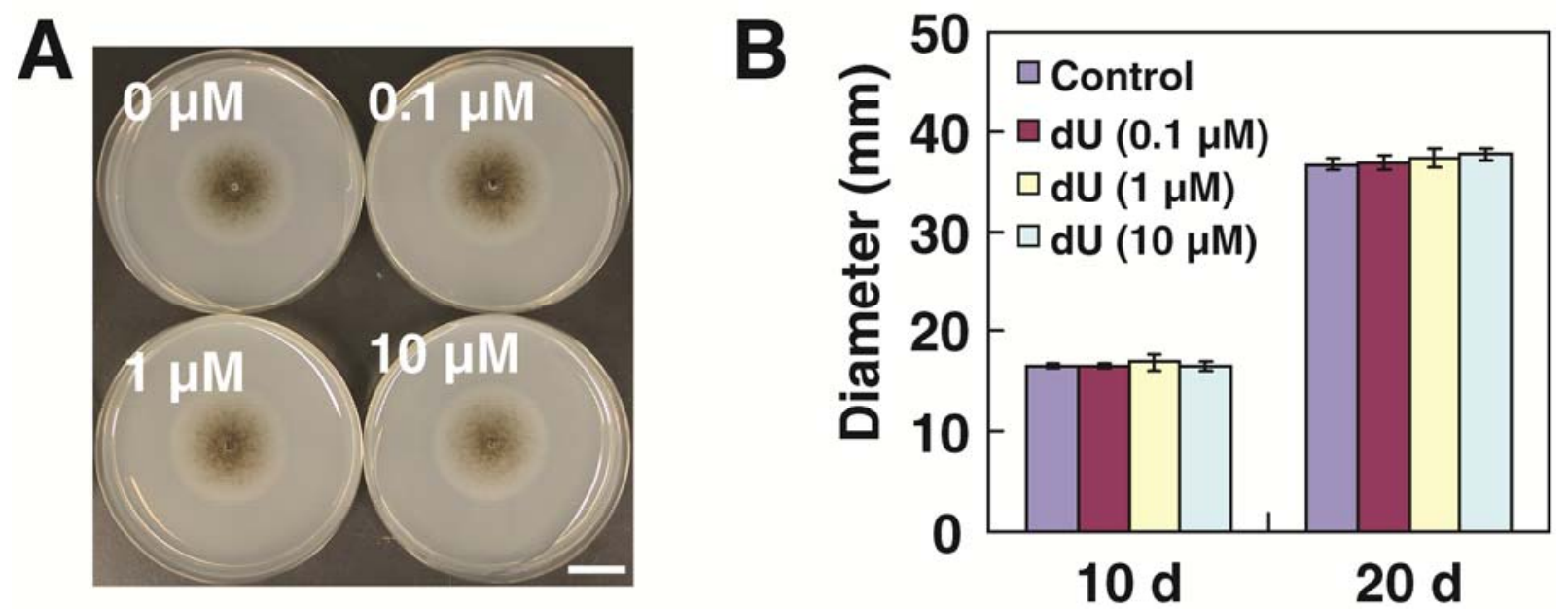

Fig. 4. Effect of 2'-deoxyuridine (dU) on fungal growth. A, Hyphal growth of Ina86-137 on minimal medium containing dU after incubation for 20 days at $25^{\circ} \mathrm{C}$. Experiments were performed three times and a representative result is shown. B, The diameters of the fungal colonies shown in A, measured after incubation for 10 and 20 days. Bars represent the means ( \pm standard deviation) of three individual culture experiments. No significant differences were detected for each treatment compared with the control $(0 \mu \mathrm{M} \mathrm{dU})$ (Tukey-Kramer's test, $P<0.05)$.
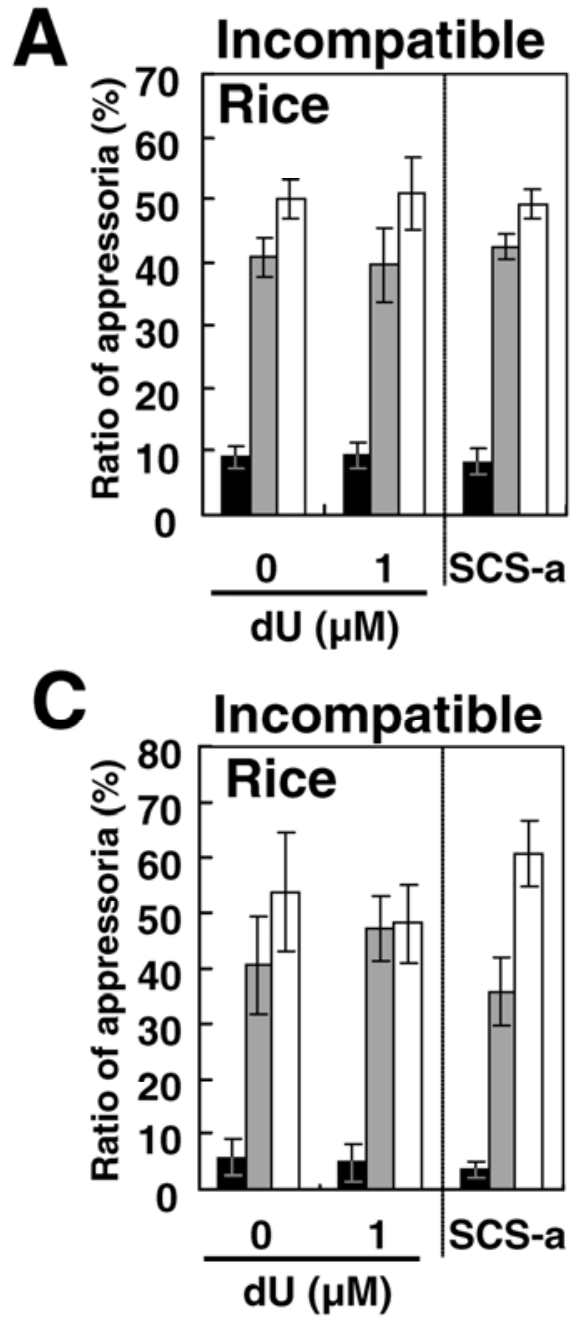

B
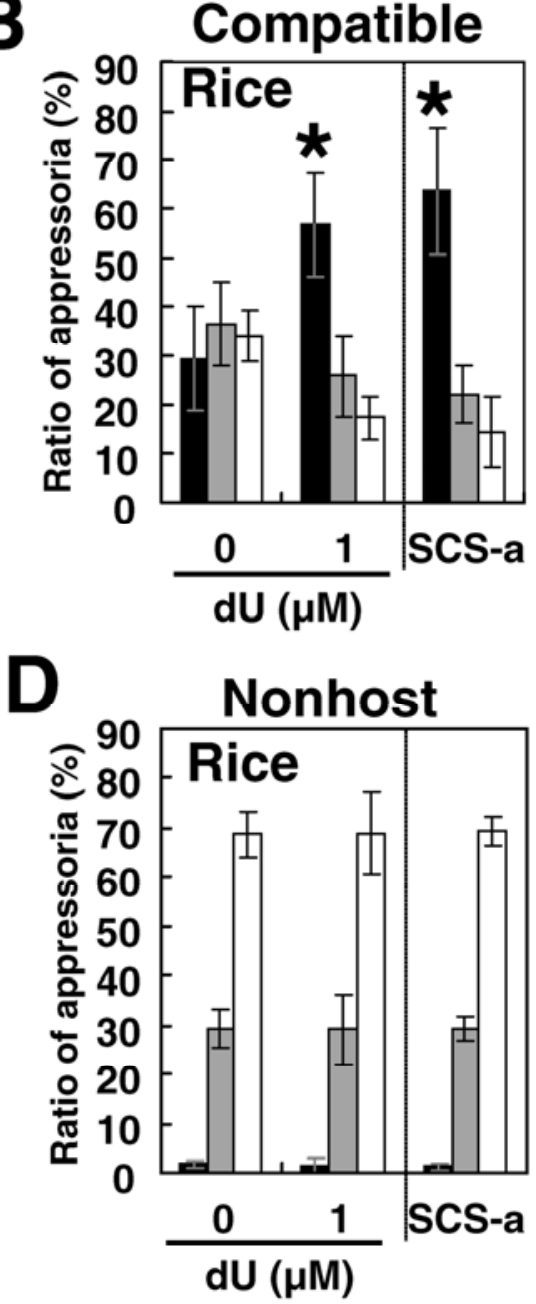

\section{- Infected $\square$ One cell infected $\square$ Uninfected}

Fig. 5. Compatible interaction-specific activity of 2'-deoxyuridine (dU) in rice. A, Washed conidia of Ina86-137, B and C, P91-15B, and D, Avena isolate 4-1 were suspended in $1 \mathrm{mM}$ MES-NaOH containing dU or SCS-a of Ina86-137 and were inoculated on the leaf sheaths of rice cv. Nipponbare (A, Pik; B, +/+; $\mathrm{C}$ and D, Pia). Bars represent the means ( \pm standard deviation) of seven to eight individual leaf sheaths. Asterisks in B denote significant differences compared with the buffer control $(0 \mu \mathrm{M} \mathrm{dU})$ (Dunnett's test, $P<0.05)$. 
regulated in response to incubation at $4^{\circ} \mathrm{C}$, in accordance with results reported in Arabidopsis (Cuevas et al. 2008), but expression levels were not altered by the addition of dU at 4 or $25^{\circ} \mathrm{C}$ (Fig. 12B). Using LC-MS-MS, we showed that dU treat- ment did not change the endogenous levels of ABA in leaf sheaths (Fig. 12C). We therefore concluded that, because dU did not affect the endogenous levels of $\mathrm{ABA}$, dU exerts its effects through an ABA-independent pathway.
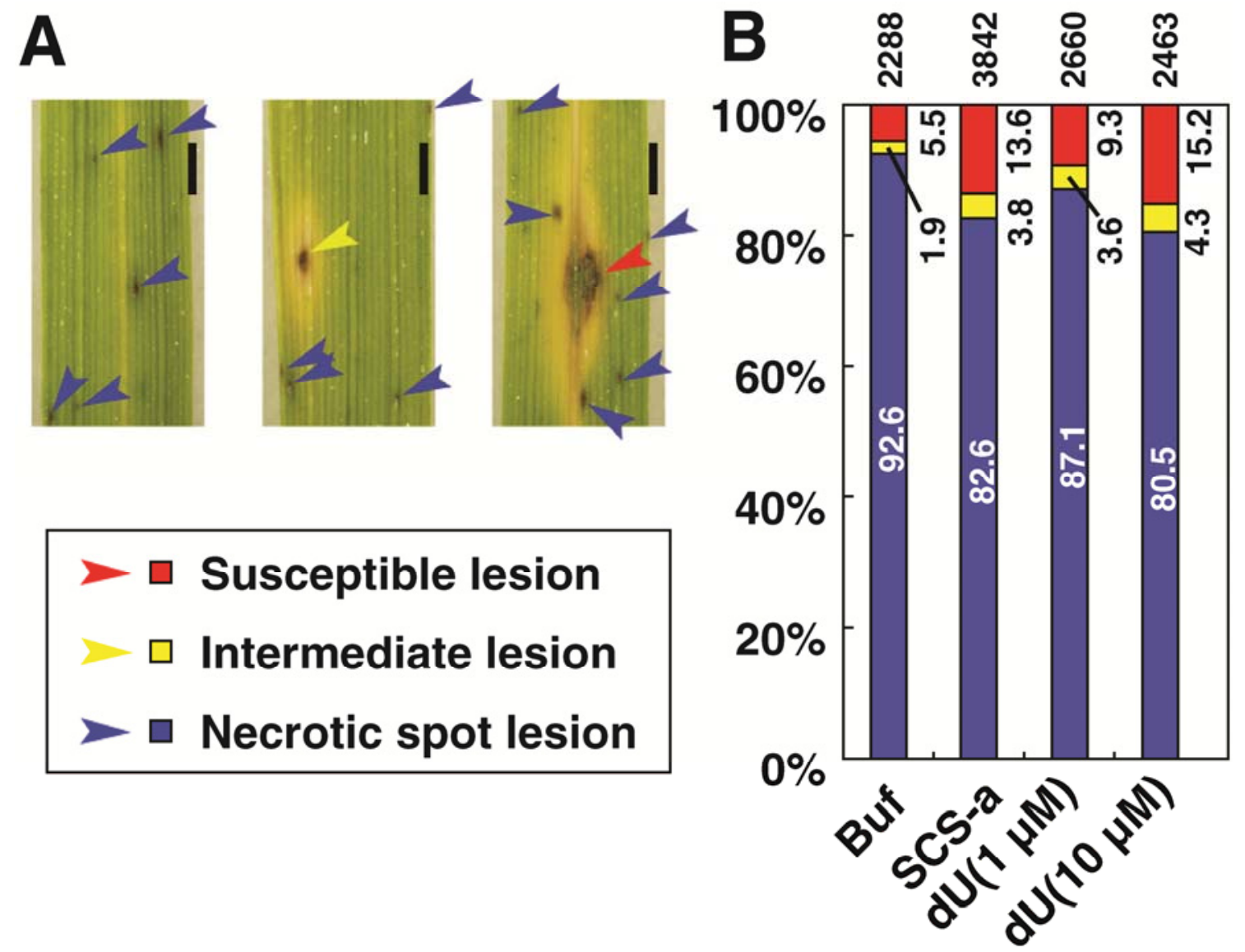

Fig. 6. Effect of 2'-deoxyuridine (dU) on lesion formation. A, Representative lesions of rice blast disease observed at 6 days postinoculation (dpi). Bars indicate $1 \mathrm{~mm}$. B, Changes in the ratio of the classes of lesions in response to the addition of dU. Washed conidia of Ina86-137 were suspended in $1 \mathrm{mM}$ MES$\mathrm{NaOH}$ (pH 5.7, Buf) containing dU or SCS-a and were then inoculated on detached leaves of rice cv. Nipponbare (Pia). The lesions were counted according to the classifications shown in A. Bars represent the ratio of lesions of each class to the total number of counted lesions in 24 individual leaf blades (indicated at the top of each bar). Three experiments were performed and a representative result is shown.


\section{$\square$ Infected $\square$ One cell infected $\square$ Uninfected}

Fig. 7. Effect of 2'-deoxyuridine (dU) on oat plants. A, Washed conidia of Avena isolate 4-1 or B, Ina86-137 were suspended in $1 \mathrm{mM}$ MES-NaOH (pH 5.7) containing dU or SCS-a of Ina86-137 and were then inoculated on the leaf sheaths of oat cv. Haeibuki. The extent of the resulting infections of 4-1 and Ina86-137 were scored at 36 and $48 \mathrm{~h}$ postinoculation (hpi), respectively. Bars represent the means ( \pm standard deviation) of five to seven individual leaf sheaths. No significant differences were detected for either treatment compared with the buffer control $(0 \mu \mathrm{M} \mathrm{dU})($ Dunnett's test, $P<0.05)$. 


\section{DISCUSSION}

In this study, we identified $\mathrm{dU}$ as the molecule responsible for the infection-promoting activity of rice blast fungus SCS (Figs. 1 to 3). Our results also suggest that SCS includes infection-promoting factors other than $\mathrm{dU}$, because minor activities were detected in several fractions after separation by HPLC (Fig. 2B), and the formation of susceptible lesions with comparable frequency to those treated with SCS-a required $10 \mu \mathrm{M}$ $\mathrm{dU}, 90$ times the concentration found in a standard preparation of SCS-a (Fig. 6B).

In the methanol-soluble fraction from the five isolates of rice blast fungus other than Ina86-137, a peak on the HPLC chromatogram indistinguishable from that of dU was observed (data not shown). Taken together with the observation that $\mathrm{dU}$ promoted the infection of susceptible rice plants by two different isolates of rice blast fungus, Ina86-137 and P91-15B(Fig. 5 ), it appears dU acts as a common yet specific infection-promoting factor in compatible interactions of rice blast fungus and susceptible rice. This hypothesis is partly supported by the observations that the action of $\mathrm{dU}$ was not observed in the compatible interaction of oat and oat blast fungus (Fig. 7) and did not induce the susceptibility of rice to oat blast fungus (Fig. 5), as was reported for SCS (Ando et al. 2009). As a future study, it would be interesting to examine how a wide range of phytopathogenic fungi recognize $\mathrm{dU}$ as an infectionpromoting factor.

Numerous studies have attempted to elucidate the chemical structures and biological features of the HST and suppressors that determine the host specificity of phytopathogens. HST are characterized by their ability to induce visible damage when applied to host plants, while suppressors are not. On the other hand, both HST and suppressors induce susceptibility in plants to less virulent races and even nonhost pathogens (Shiraishi et al. 1997; Wolpert et al. 2002). In our experiments, SCS did not induce visible damage in rice plants (data not shown). $\mathrm{dU}$ is also unlikely to act as a toxin, because it is a metabolite in rice. In rice blast fungi, toxins with known chemical structures are not host-specific and the production of suppressors has not been reported. Treatment with dU also did not suppress host
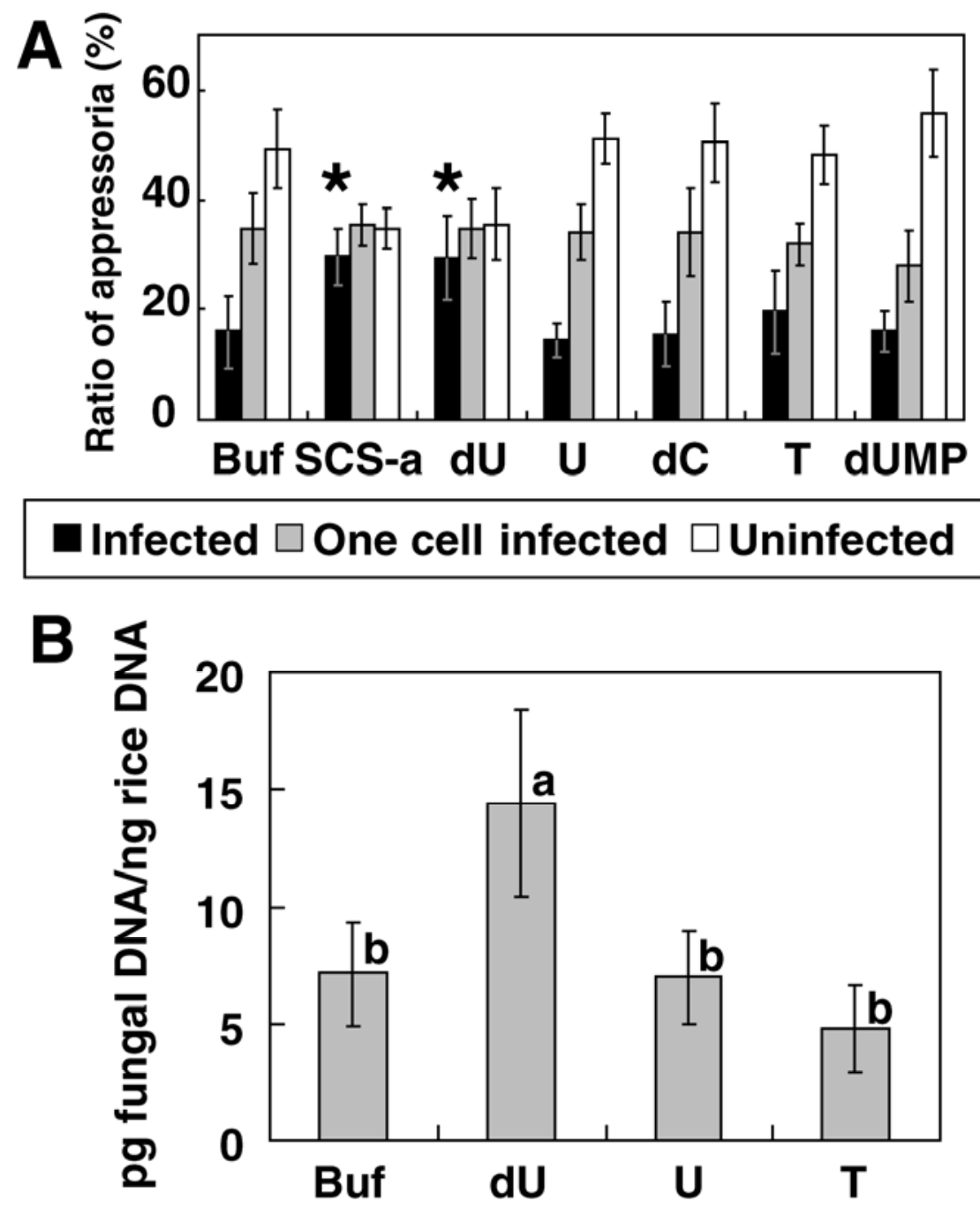

Fig. 8. Infection-promoting activity of 2'-deoxyuridine (dU)-related compounds. A, Infection-promoting activity of several dU-related compounds was evaluated in the leaf-sheath assay. Washed conidia of Ina86-137 were suspended in $1 \mathrm{mM}$ MES-NaOH (pH 5.7) containing either dU, uridine (U), 2'deoxycytidine (dC), thymidine (T), $1 \mu \mathrm{M}$ dUMP, or SCS-a and were then inoculated on the leaf sheaths of rice cv. Nipponbare (Pia). Bars represent the means $( \pm$ standard deviation $[S D]$ ) of seven individual leaf sheaths. Asterisks denote significant differences compared with the buffer control (Buf, $1 \mathrm{mM}$ MES-NaOH, pH 5.7) (Dunnett's test, $P<0.05$ ). B, Fungal biomass in leaf sheaths in response to treatment with dU, U, and T, as measured by quantitative polymerase chain reaction (qPCR) of fungal and rice DNA. Leaf sheaths of Nipponbare (Pia) were inoculated with washed Ina86-137 conidia in the presence of $1 \mu \mathrm{M} \mathrm{dU}$, uridine (U) or thymidine (T). At $72 \mathrm{~h}$ postinoculation (hpi), fungal biomass was measured by qPCR. Bars represent the mean $( \pm \mathrm{SD})$ of five individual leaf sheaths. The experiment was repeated twice and a typical result is shown. Different letters denote significant differences (Tukey-Kramer's test, $P<0.05)$. Buf, $1 \mathrm{mM}$ MES-NaOH, pH 5.7. 
defense responses, including the expression of PR genes and production of $\mathrm{H}_{2} \mathrm{O}_{2}$ and phytoalexins, in rice infected with virulent rice blast fungus isolates (Figs. 9 to 11). These characteristics of dU strongly indicate that the mode of action of $\mathrm{dU}$ is distinct from that of a suppressor.

In previous studies, SGF of a rice blast fungus induced susceptibility to a nonhost fungal pathogen of rice, A. alternata, in the natural hosts of rice blast fungus, including barley and perennial ryegrass (Fujita et al. 1994). These findings indicate that SGF contributes to the establishment of a basal compatibility between rice plants and nonhost pathogens. The susceptibilityinducing activity of SGF was increased by prolonged incubation of conidial suspensions of rice blast fungus and was specifically detected in the ethyl acetate-soluble fraction (Arase et al. 1990; Fujita et al. 1995). Here, in contrast, dU was detected as a preexisting factor in SCS and was insoluble in ethyl acetate (Fig. 1). Similar to SCS (Ando et al. 2009), dU did not alter nonhost resistance of rice plants (Fig. 5). From these observations, we conclude that the mode of action of dU is distinct from that of the susceptibility-inducing factor in SGF.

The salvage pathway of pyrimidine nucleoside synthesis is widely distributed in eukaryotic cells, and the produced nucleosides are typically incorporated into DNA. Microarray analyses of gene expression in rice blast fungus revealed no drastic upregulation of a putative cytidine deaminase gene (MGG 14549.6) that converts cytidine to dU during the forma- tion of appressoria (National Center for Biotechnology Information Gene Expression Omnibus website). However, this result does not exclude the possibility that the pyrimidine salvage pathway is activated after fungal penetration of host cells to supply substrates for fungal DNA, the amount of which increases as the infection proceeds (Fig. 3). In addition, the activation of the salvage pathway may be accompanied by concomitant elevation of the levels of pathway intermediates, including $\mathrm{dU}$, which is recognized by rice blast fungus as an infection-promoting factor. These speculations are suitable topics for future investigations.

None of the dU-related compounds examined here showed infection-promoting activity (Fig. 8). As these compounds are considered to be metabolized in the pyrimidine salvage pathway following incorporation into rice or rice blast fungus cells, dU may act outside of rice or rice blast fungus cells in a structure-specific manner. Furthermore, the observation that the dose-dependent effect of dU reached a plateau at $100 \mathrm{nM}$ (Fig. $3 \mathrm{~A}$ ) indicates the presence of a dU-specific recognition system either in rice or rice blast fungus. Although we detected dU in the SCS of rice blast fungus, it remains unclear whether dU was supplied from rice or the rice blast fungus at the site of interaction. Notably, hyphal growth in planta (Figs. 3, 5, and 8) but not in vitro (Fig. 4) was stimulated by dU. Therefore, it is possible that dU acts in rice blast fungus in planta through the expression of genes, such as effectors, that control pathoge-
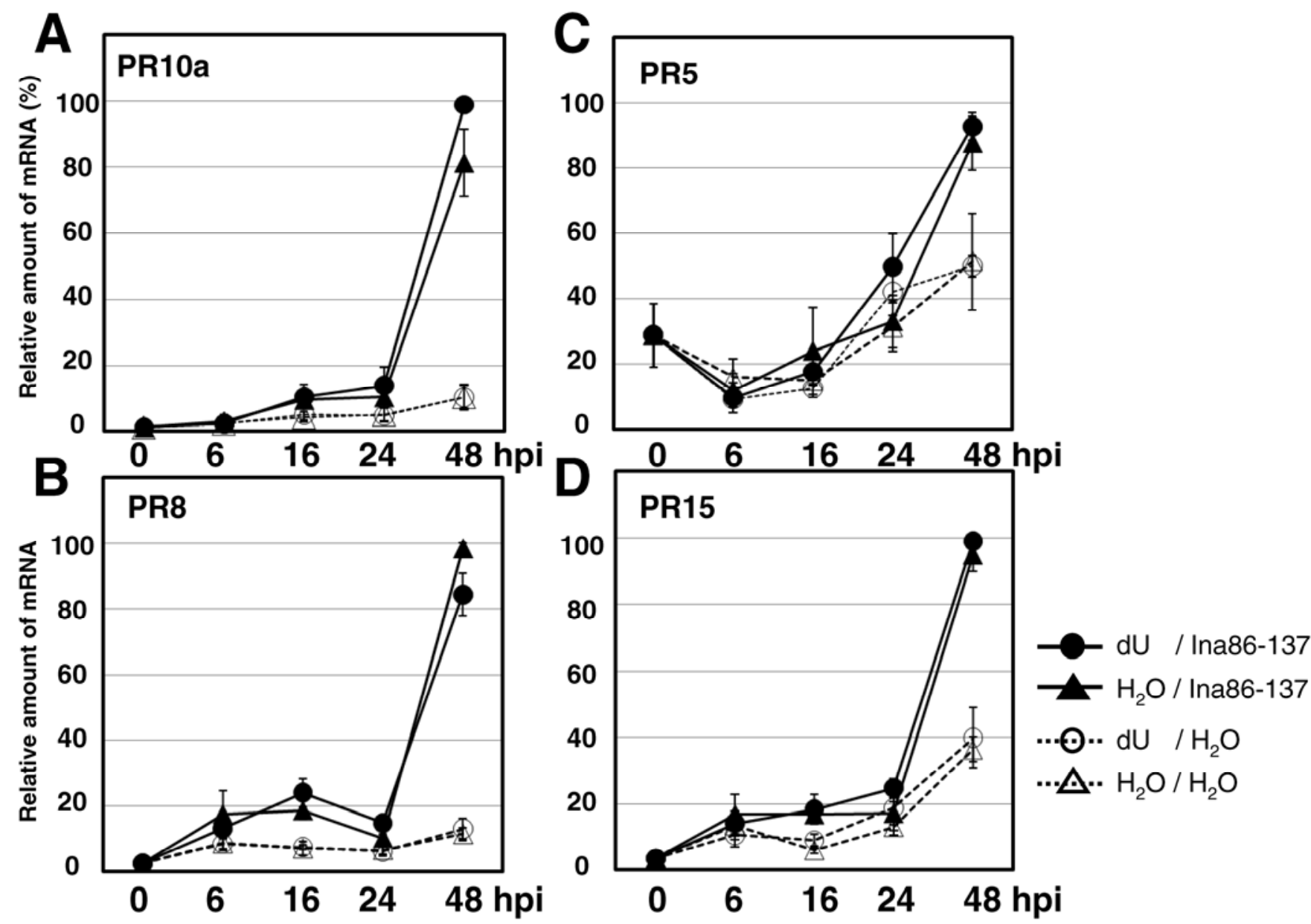

Fig. 9. Effect of 2'-deoxyuridine (dU) on the expression of genes encoding pathogenesis related (PR) proteins in the leaf sheaths of rice during compatible interaction. Washed Ina86-137 conidia were suspended in $1 \mathrm{mM}$ MES-NaOH (pH 5.7) containing 0 or $1 \mu \mathrm{M}$ dU and were then inoculated on the leaf sheaths of rice cv. Nipponbare (Pia). Total RNAs were extracted at 6, 16, 24, and $48 \mathrm{~h}$ postinoculation (hpi) and were subjected to quantitative reverse-transcription polymerase chain reaction using primers specific to A, PR10a, B, PR8, C, PR5, and D, PR15. No significant differences were detected for any treatment compared with the control experiments $(0 \mu \mathrm{M} \mathrm{dU})$ (Tukey-Kramer's test, $P<0.05)$. 
nicity. To our knowledge, no studies have investigated the modification of gene expression in phytopathogens by selfproduced toxins and suppressors.

Jiang and associates (2010) reported that exogenous treatment of rice cv. Nipponbare (Pia) with ABA drastically weakened both basal resistance and Pia-driven resistance to rice blast fungus via actions on the salicylic acid (SA)-signaling pathway, which is considered to play key roles in both compatible and incompatible interactions. Their results indicate that ABA blocks signaling downstream of Pia action during incompatible interactions. Our present data indicates that dU acts upstream of Pia and, likely, even Pik, as dU did not affect these two resistance gene-mediated incompatible interactions (Fig. 5). Jiang and
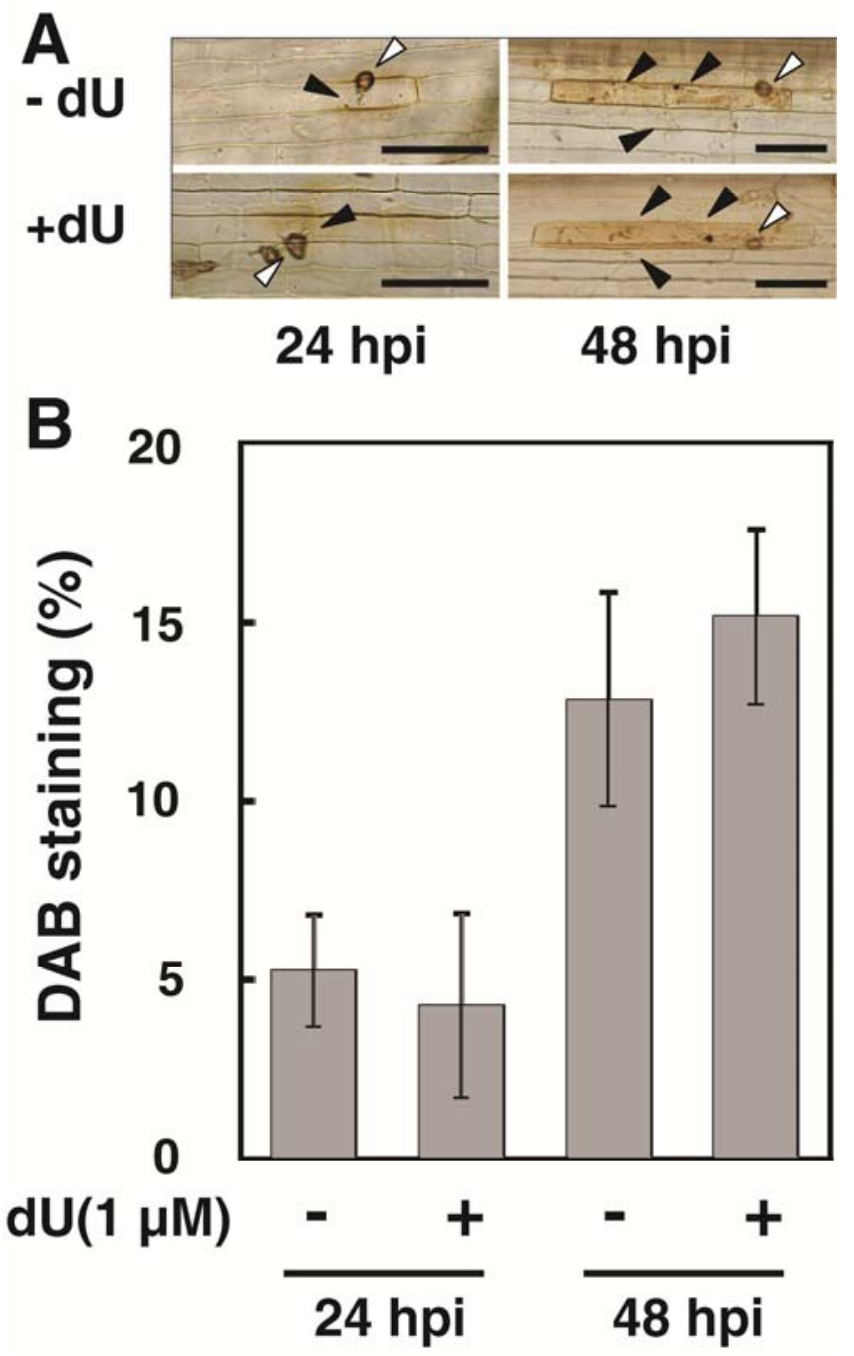

Fig. 10. Effect of 2'-deoxyuridine (dU) on the accumulation of $\mathrm{H}_{2} \mathrm{O}_{2}$ in the leaf sheaths of rice during compatible interactions. Washed conidia of Ina86-137 were suspended in $1 \mathrm{mM}$ MES-NaOH ( $\mathrm{pH}$ 5.7) containing dU at $1 \mu \mathrm{M}$ and were inoculated on the leaf sheaths of rice cv. Nipponbare (Pia). At 24 and $48 \mathrm{~h}$ postinoculation (hpi), $\mathrm{H}_{2} \mathrm{O}_{2}$ was visualized by 3',3diaminobenzidine tetrahydrochloride (DAB) staining. A, Representative DAB-staining patterns in a rice epidermal cell of a leaf sheath inoculated with rice blast fungus in the absence or the presence of $1 \mu \mathrm{M} \mathrm{dU}$ at $24 \mathrm{hpi}$. Open and filled arrowheads indicate appressorium and infectious hyphae, respectively. Bars indicate $50 \mu \mathrm{m}$. B, Ratio of appressoria that induced DAB-positive signals in the epidermal cells of leaf sheaths. Greater than 100 appressoria per leaf sheath were observed at $24 \mathrm{hpi}$, and appressoria with DAB signals directly beneath their contact points in leaf sheaths were counted. No significant differences were detected for any treatment compared with the control experiments $(0 \mu \mathrm{M} \mathrm{dU})$ (Tukey-Kramer's test, $P<$ $0.05)$. Bars represent the averages of three to five leaf sheaths \pm standard deviation. associates (2010) also demonstrated that ABA is present in both hyphae and conidia of rice blast fungus and can be secreted into culture fluid; therefore, SCS likely contains ABA. As previously reported by Koga and associates (2004), ABA displayed infection-promoting effects similar to those of $\mathrm{dU}$ in the leaf-sheath assay (Fig. 12), although the required concentration for activity was 200-fold higher than that of dU (Fig. 3). ABA may not have been identified as an infection-promoting factor in SCS because it was present in amounts below the threshold of detection in the leaf-sheath assay.

In conclusion, we know of no reports that have examined the physiological actions of pyrimidine nucleosides in higher plants, with the exception of uridine, which stimulates adventitious root formation in a number of plant species (Tamimi 2003) and induces cortical-cell division in leguminous plants at early stages of nodule formation in cooperation with plant hormones (Smit et al. 1995) and $N$-acetylchitooligosaccharides (Schlaman et al. 1997). Although the SCS of rice blast fungus contains uridine in addition to dU (Fig. 2C, peak c), the biological significance of this finding is unclear. Further studies are required to clarify the mode of action of $\mathrm{dU}$ and the roles of other signal molecules of fungal origin in rice-rice blast fungus interactions.

\section{MATERIALS AND METHODS}

Plants, pathogens, and chemicals.

Three near-isogenic lines of rice plants (Oryza sativa L. cv. Nipponbare) carrying the blast-resistance genes Pia (Nipponbare $[P i a])$ and Pik (Nipponbare $[P i k])$ and null forms of these genes (Nipponbare $[+/+]$ ) were used in this study. Rice plants were routinely grown in a chamber under a 14 -h-light $\left(28^{\circ} \mathrm{C}\right)$ and 10 -h-dark $\left(24^{\circ} \mathrm{C}\right)$ cycle in hydroponic culture, as previously described in Tanabe and associates (2006). Oat plants (Avena sativa L. cv. Haeibuki) were grown in soil-filled pots in a chamber under a 14-h-light $\left(28^{\circ} \mathrm{C}\right)$ and 10 -h-dark $\left(24^{\circ} \mathrm{C}\right)$ cycle. The following strains of $M$. oryzae were used: oryzae isolates Ina86-137 (MAFF 101511, race, 007.0, virulent to Pia), P91-15B (001.0, virulent to ++), and Avena isolate 4-1 (MAFF 306606, virulent to Haeibuki). Synthetic dU was purchased from Sigma-Aldrich Co., Ltd. (St. Louis). All other chemicals were purchased from Wako Pure Chemical Industries (Osaka, Japan) unless otherwise stated.

\section{Preparation of conidia and the supernatant of a conidial suspension.}

Blast fungi were grown on oatmeal agar (30 g oatmeal, $5 \mathrm{~g}$ sugar, and $16 \mathrm{~g}$ agar per liter of water) in petri dishes incubated at $25^{\circ} \mathrm{C}$ for 9 days. Conidial suspensions were prepared according to Koga (1994), and then, were filtered through two layers of Miracloth (Calbiochem, La Jolla, CA, U.S.A.) to remove cell debris. Washed conidia and SCS were prepared as described previously (Ando et al. 2009). The concentration of total neutral sugars in SCS was measured by a phenol/sulfate method using glucose as a standard sugar. Conidia of blast fungi were suspended in SCS adjusted to $40 \mu \mathrm{g}$ of glucose equivalent per milliliter (SCS-a), as previously described (Ando et al. 2009).

\section{Fungal inoculation and microscopic observations.}

To determine the level of infectivity, washed conidia were suspended at a concentration of $1 \times 10^{5}$ cells ml ${ }^{-1}$ in a solution containing $1 \mathrm{mM}$ MES-NaOH (pH 5.7) or SCS-a. Sheaths of the fourth leaves of rice plants at the 4.5-leaf stage (3 to 4 weeks old) were excised and inoculated with a suspension of conidia and were incubated at $25^{\circ} \mathrm{C}$ in the dark for $48 \mathrm{~h}$, unless otherwise stated. After fixation in a solution containing $5 \%$ (vol/vol) formaldehyde, $5 \%$ (vol/vol) acetic acid, and $45 \%$ (vol $/ \mathrm{vol})$ etha- 
nol, the level of infection was determined from the ratio of intact appressoria counted under a light microscope. The samples were scored as "infected" (Fig. 1A), "one cell infected" (Fig. 1B), or "uninfected" (Fig. 1C), corresponding to appressoria that infected more than one rice cell beneath the appressorium, one cell, or no cells, respectively (Tanabe et al. 2006). Visualization of $\mathrm{H}_{2} \mathrm{O}_{2}$ by DAB staining was performed as described previously (Tanabe et al. 2009). Washed conidia of Ina86-137 were adjusted to $1 \times 10^{5}$ cells $\mathrm{ml}^{-1}$ in $1 \mathrm{mM}$ MES-NaOH (pH 5.7) and were inoculated onto three to five sheaths of leaves of Nipponbare (Pia). More than 100 appressoria per leaf sheath were observed at $24 \mathrm{hpi}$, and the appressoria with DAB signals beneath them were then counted.

To examine fungal lesions, fourth-leaf blades were detached from 15-day-old plants and were placed on moistened filter paper in petri dishes. Washed conidia were suspended to $1 \times$ $10^{5}$ cells $\mathrm{ml}^{-1}$ in SCS-a and were sprayed on the leaf blades, which were incubated at $25^{\circ} \mathrm{C}$ in the dark for $24 \mathrm{~h}$, followed by 14-h-light and 10-h-dark cycles for 5 days. Lesions were classified as reported previously (Ando et al. 2009; Fig. 6A), necrotic spots (resistant dark brown specks), intermediate lesions (yellow and brown lesions without a gray center), and susceptible lesions (those areas with a gray center and emerging aerial hyphae and conidia).

\section{Fractionation of SCS.}

Following the lyophilization of SCS, dry weight was determined and the dried material was then resuspended in distilled water. After incubation at $100^{\circ} \mathrm{C}$ for 15 min to eliminate catalase activity (Tanabe et al. 2008), insoluble materials were removed by centrifugation at $1,710 \times g$ for $15 \mathrm{~min}$ and filtration through a $0.20 \mu \mathrm{m}$ filter (Sartorius, Goettingen, Germany). The resultant solution was extracted three times with equal volumes of ethyl acetate (EAF). The aqueous phase was lyophilized and dissolved in methanol (MF), while the methanolinsoluble materials were further extracted with water (WF). Each fraction was dried under vacuum; EAF was dissolved in methanol at $10 \mu \mathrm{g} \mathrm{dw} \mu \mathrm{l}^{-1}, \mathrm{MF}$ was dissolved in water at $80 \mu \mathrm{g}$ $\mathrm{dw} \mu \mathrm{l}^{-1}$, and WF was dissolved in water at $30 \mu \mathrm{g} \mathrm{dw} \mu \mathrm{l}^{-1}$.

MF was separated on a reverse-phase HPLC column (Inertsil ODS-3, $10 \times 250 \mathrm{~mm}$; GL Sciences; Tokyo), eluted with mobile phase A (water/methanol $=3: 1[\mathrm{vol} / \mathrm{vol}]$ ) at a flow rate of $1 \mathrm{ml} \mathrm{min}^{-1}$, and the absorbance was monitored at 220 and $245 \mathrm{~nm}$. Ten minutes after injection into the column, $451-\mathrm{ml}$ fractions were collected and combined into eight fractions (I to VIII), as shown in Figure 2A. The samples were lyophilized, were dissolved in $1 \mathrm{mM}$ MES-NaOH (pH 5.7), and were normalized to the SCS equivalent, and infection-promoting activity was then measured by the leaf-sheath assay. Fraction III (retention time 18 to $22 \mathrm{~min}$; Fig. 2A) was further separated on the identical column and was eluted with mobile phase $\mathrm{B}$ (water/ methanol $=9: 1[\mathrm{vol} / \mathrm{vol}])$ at the identical flow rate used previously. Twenty minutes after injection, $401-\mathrm{ml}$ fractions were collected, were combined into eight fractions (a to h) as shown in Figure 2C, and were then processed as described above.

\section{${ }^{1} \mathrm{H}$ NMR spectroscopy and}

high resolution mass spectrometry.

${ }^{1} \mathrm{H}$ NMR spectra were measured on a Bruker AVANCE-500 spectrometer (Bruker, Rheinstetten, Germany) in $\mathrm{D}_{2} \mathrm{O}$. The resonance of methanol at $\delta_{\mathrm{H}} 3.30$ was used as an internal reference. FABMS was recorded on a JEOL JMS-700QQ spectrometer (Akishima, Japan) using $m$-nitrobenzyl alcohol as a matrix.

\section{Fungal biomass detection.}

Sheaths of the fifth leaves of the rice plant cv. Nipponbare (Pia) were inoculated with Ina86-137 conidia $\left(4 \times 10^{5}\right.$ conidia $\mathrm{ml}^{-1}$ ) suspended in $1 \mathrm{mM}$ MES-NaOH $(\mathrm{pH} 5.7)$ and $\mathrm{dU}$ at 1 $\mu \mathrm{M}$. Four leaf sheaths per sample were harvested at 48 and 72 hpi, and total DNA was isolated by the cetyltrimethylammonium bromide method. Fungal biomass in the inoculated tissue was quantified based on the amount of fungal and host plant DNA according to Zellerhoff and associates (2006), with slight modifications. To detect fungal genomic DNA encoding 28S rRNA, primers were designed as reported by Qi and Yang (2002). A rice-specific primer pair was designed to quantify the amount of rice genomic DNA containing the OsWRKY76 gene (accession number, AK068337). qPCR was performed using an MX3000P (Stratagene, La Jolla, CA, U.S.A.) with SYBR Premix Ex Taq II (Takara Co., Ltd, Ohtsu, Japan), following the manufacturer's instructions.



Fig. 11. Effect of 2'-deoxyuridine (dU) on the accumulation of phytoalexins in leaf sheaths. Washed conidia of Ina86-137 were suspended in 1 mM MES$\mathrm{NaOH}$ (pH 5.7) containing dU and were then inoculated on the leaf sheaths of rice cv. Nipponbare (Pia). At $48 \mathrm{~h}$ postinoculation (hpi), phytocassanes, momilactones, and sakuranetin were extracted and measured. Bars represent the mean and standard error of three individual samples using four to five leaf sheaths. Experiments were repeated three times and a typical result is shown. No significant differences in the levels of phytoalexins were detected compared with the buffer control (Dunnett's test, $P<0.05$ ). 

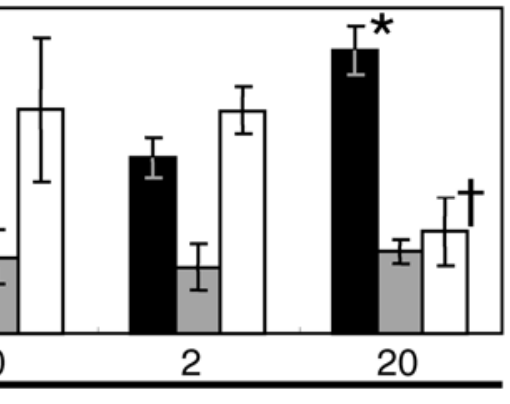

$\operatorname{ABA}(\mu \mathrm{M})$

Infected $\square$ One cell infected $\square$ Uninfected

B

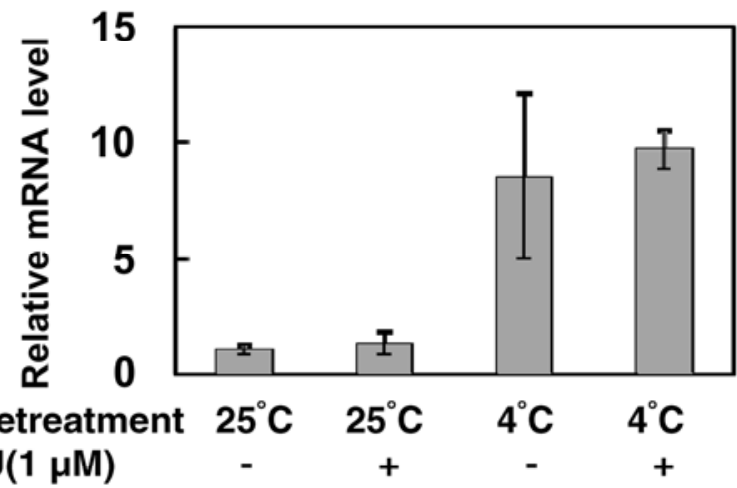

C

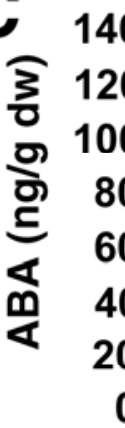

$\mathrm{dU}(1 \mu \mathrm{M})$
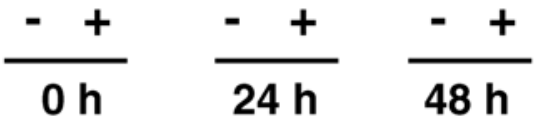

Fig. 12. Effects of exogenous abscissic acid (ABA) and 2'-deoxyuridine $(\mathrm{dU})$ on infection and endogenous ABA concentrations in leaf sheaths. A Effect of ABA in the leaf-sheath assay. Washed conidia of Ina86-137 were suspended in $1 \mathrm{mM}$ MES-NaOH (pH 5.7) containing 2 or $20 \mu \mathrm{M}$ ABA and were then inoculated on leaf sheaths of rice cv. Nipponbare (Pia). Bars represent the means ( \pm standard deviation $[\mathrm{SD}]$ ) of five to six individual leaf sheaths. An asterisk and dagger denote a significant increase or decrease in the ratio of infected and uninfected appressoria, respectively, compared with the buffer control $(0 \mu \mathrm{M}$ ABA) (Dunnett's test, $P<0.05)$. B, Effect of dU and low-temperature treatment on the level of OsNCED3 mRNA. Leaf sheaths of Nipponbare (Pia) were incubated at 25 or $4{ }^{\circ} \mathrm{C}$ for $4 \mathrm{~h}$ in the absence or the presence of $1 \mu \mathrm{M} d \mathrm{dU}$, and total RNAs were then isolated and subjected to quantitative reverse-transcription polymerase chain reaction. Bars represent the means $( \pm \mathrm{SD})$ of three independent experiments using three individual leaf sheaths. No significant differences were detected for any treatment compared with the control experiments $(0$ $\mu \mathrm{M}$ dU) (Tukey-Kramer's test, $P<0.05$ ). C, Levels of endogenous ABA in rice leaf sheaths. Leaf sheaths of Nipponbare $(\mathrm{Pia})$ were incubated at $25^{\circ} \mathrm{C}$ for the time indicated in the absence or the presence of $1 \mu \mathrm{MdU}$, and total ABA was measured. Bars represent the means $( \pm \mathrm{SD})$ of three independent experiments using four individual leaf sheaths. No significant differences were detected for any treatment compared with the control experiments $(0 \mu \mathrm{M} d \mathrm{dU})$ (Tukey-Kramer's test, $P<0.05)$.
RNA isolation and qRT-PCR.

Total RNA was extracted from the leaf sheaths of rice plants using Sepasol RNA I Super (Nacalai Tesque, Kyoto, Japan). After digestion with RQ1 RNase-free DNase (Promega, Madison, WI, U.S.A.), 0.5 or $1 \mu \mathrm{g}$ of total RNA was used for first-strand cDNA synthesis with a PrimeScript RT reagent kit (Takara Co., $\mathrm{Ltd})$. The relative levels of gene expression were quantified on a sequence detection system (MX3000P, Stratagene) using rice $18 \mathrm{~S}$ or $25 \mathrm{~S}$ rRNA as an internal standard. The sequences of the primer pairs are listed in Supplementary Table S1.

\section{Determination of phytoalexins.}

Sheaths of the fourth leaves of 3-week-old rice cv. Nipponbare (Pia) were inoculated with Ina86-137, as already described. After incubation at $25^{\circ} \mathrm{C}$ in the dark for $48 \mathrm{~h}$, both edges of the sheaths (approximately $1 \mathrm{~cm}$ in length) were removed and the residual parts were extracted with $79 \%$ (vol/vol) ethanol containing $14 \%(\mathrm{vol} / \mathrm{vol})$ water, $7 \%(\mathrm{vol} / \mathrm{vol})$ acetonitrile, and $0.01 \%$ (vol/ $\mathrm{vol}$ ) acetic acid at $96^{\circ} \mathrm{C}$ for $20 \mathrm{~min}$. Samples were analyzed for the simultaneous determination of momilactones, phytocassanes, and sakuranetin using HPLC-MS/MS (Shimizu et al. 2008). Phytoalexin levels were determined with combinations of the precursor and product ions $(\mathrm{m} / \mathrm{z} 317 / 299$ for phytocassanes $\mathrm{A}, \mathrm{D}$, and $\mathrm{E}, \mathrm{m} / \mathrm{z} 335 / 317$ for phytocassane $\mathrm{B}$, $\mathrm{m} / \mathrm{z} 319 / 301$ for phytocassane $\mathrm{C}, \mathrm{m} / \mathrm{z} 315 / 271$ for momilactone $\mathrm{A}, \mathrm{m} / \mathrm{z} 331 / 269$ for momilactone $\mathrm{B}$, and $\mathrm{m} / \mathrm{z} 287 / 167$ for sakuranetin) in the multiple-reaction monitoring mode.

\section{Determination of ABA.}

Sheaths of the fourth leaves of 3-week-old rice cv. Nipponbare (Pia) were excised and incubated at $25^{\circ} \mathrm{C}$ for $6 \mathrm{~h}$, and were then inoculated with Ina86-137. Leaf sheaths were harvested at 24 and $48 \mathrm{hpi}$, were immediately frozen in liquid nitrogen, and were lyophilized, and their dry weights were measured. The dried sheaths $(20 \mathrm{mg}$ of $\mathrm{dw})$ were then subjected to extraction with $1 \mathrm{ml}$ of $80 \%$ ( $\mathrm{vol} / \mathrm{vol}$ ) acetonitrile containing $1 \%$ (vol/vol) acetic acid and $2 \mathrm{ng} \mathrm{d}_{6}$-ABA (Icon Isotopes, Summit, NJ, U.S.A.) for $1 \mathrm{~h}$. After centrifugation, the supernatants were collected, and the residues were extracted again with $80 \%$ acetonitrile containing $1 \%$ acetic acid for $10 \mathrm{~min}$. Combined supernatants were purified and endogenous ABA levels were quantified as previously described (Yoshimoto et al. 2009).

\section{Fungal culture on minimal medium.}

Mycelia of the rice blast fungus Ina86-137 were cultured on minimal medium with or without the supplementation of dU $(0.1,1$, and $10 \mu \mathrm{M})$ at $25^{\circ} \mathrm{C}$ in the dark for 20 days. Minimal medium was prepared according to Crawford and associates (1986), with slight modifications: $1 \times$ Vigol's $\mathrm{N}$ salt $(50 \times$ Vigol's $\mathrm{N}$ salt solution $=125 \mathrm{~g} \mathrm{Na}$ citrate $\cdot 2 \mathrm{H}_{2} \mathrm{O}, 100 \mathrm{~g}$ $\mathrm{NH}_{4} \mathrm{NO}_{3}$-anhydrous, and $10 \mathrm{~g} \mathrm{MgSO}_{4} \cdot 7 \mathrm{H}_{2} \mathrm{O}$ and $5 \mathrm{~g}$ $\mathrm{CaCl}_{2} \cdot 2 \mathrm{H}_{2} \mathrm{O}$ in 1 liter water), $0.01 \%$ (vol $/ \mathrm{vol}$ ) trace elements (4.57 $\mathrm{g}$ of citric acid, $5 \mathrm{~g}$ of $\mathrm{ZnSO}_{4} \cdot 7 \mathrm{H}_{2} \mathrm{O}, 0.709 \mathrm{~g}$ of $\mathrm{FeSO}_{4} \cdot 7 \mathrm{H}_{2} \mathrm{O}, 0.337 \mathrm{~g}$ of $\left(\mathrm{NH}_{4}\right)_{2} \mathrm{SO}_{4}, 0.25 \mathrm{~g}$ of $\mathrm{CuSO}_{4} \cdot 5 \mathrm{H}_{2} \mathrm{O}$ $0.0713 \mathrm{~g}$ of $\mathrm{MnSO}_{4} \cdot 4-6 \mathrm{H}_{2} \mathrm{O}, 0.05 \mathrm{~g}$ of $\mathrm{H}_{3} \mathrm{BO}_{4}$.anhydrous, and $0.05 \mathrm{~g}$ of $\mathrm{Na}_{2} \mathrm{MoO}_{4} \cdot 2 \mathrm{H}_{2} \mathrm{O}$, in $100 \mathrm{ml}$ of water), $0.1 \%$ ( $\left.\mathrm{vol} / \mathrm{vol}\right)$ vitamin supplements $(1 \mathrm{mg}$ of thiamine- $\mathrm{HCl}$ and $5 \mu \mathrm{g}$ of biotin per milliliter), $1 \%$ (wt/vole) sucrose, and $1.5 \%$ (wt/vole) agar, $\mathrm{pH} 7.3$.

\section{ACKNOWLEDGMENTS}

We are grateful to M. Hasegawa of Ibaraki University, J. Koga of Meiji Seika Kaisha, Ltd., and H. Satoh of National Crop Science for the supply of standard compounds, including momilactones, phytocassanes, and rice seeds of Nipponbare BL no. 5 (Pik), and to Y. Take of the National Institute of Aerobiological Sciences for extensive editorial work 
on the manuscript. A Japanese oryzae isolate of $M$. oryzae Ina86-137 (MAFF 101511, race 007.0) and Avena isolate 4-1 (MAFF 306606) were supplied by the National Institute of Aerobiological Sciences (Tsukuba, Japan) Gene bank. This work was supported by a grant from the Program for Promotion of Basic Research Activities for Innovative Biosciences.

\section{LITERATURE CITED}

Ando, S., Tanabe, S., Akimoto-Koriyama, C., Nishizawa, Y., and Minami, E. 2009. The supernatant of a conidial suspension of Magnaporthe oryzae contains a factor that promotes the infection of rice plants. J. Phytopathol. 157:420-426.

Asselbergh, B., De Vleesschauwer, D., and Höfte, M. 2008. Global switches and fine-tuning: ABA modulates plant pathogen defense. Mol. PlantMicrobe Interact. 21:709-719.

Arase, S., Kinoshita, S., Kano, M., Nozu, M., Tanaka, E., and Nishimura, S. 1990. Studies on host-selective infection mechanism of Pyricularia oryzae Cavara (2): Production of susceptibility-inducing factor(s) from germinating spores and their phytotoxicity. Ann. Phytopath. Soc. Jpn. 56:322-330.

Chen, S., Xu, X., Dai, X., Yang, C., and Qiang, S. 2007. Identification of tenuazonic acid as a novel type of natural photosystem II inhibitor binding in QB-site of Chlamydomonas reinhardtii. Biochim. Biophys. Acta 1767:306-318.

Christmann, A., Moes, D., Himmelbach, A., Yang, Y., Tang, Y., and Grill, E. 2006. Integration of abscisic acid in signaling into plant responses. Plant Biol. 8:314-325.

Crawford, M. S., Chumley, F. G., Weaver, C. G., and Valent, B. 1986. Characterization of the heterokaryotic and vegetative diploid phases of Magnaporthe grisea. Genetics 114:1111-1129.

Cuevas, J. C., López-Cobollo, R., Alcázar, R., Zarza, X., Koncz, C., Altabella, T., Salinas, J., Tiburcio, A. F., and Ferrando, A. 2008. Putrescine is involved in Arabidopsis freezing tolerance and cold acclimation by regulating abscisic acid levels in response to low temperature. Plant Physiol. 148:1094-1105.

de Jong, J. C., McCormack, B. J., Smirnoff, N., and Talbot, N. J. 1997. Glycerol generates turgor in rice blast. Nature 389:244-245.

Dewey, R. E., Siedow, J. N., Timothy, D. H., and Levings, C. S., III. 1988 A 13-kilodalton maize mitochondrial protein in E. coli confers sensitivity to Bipolaris maydis toxin. Science 239:293-295.

Dixon, R. A., and Lamb, C. J. 1990. Molecular communication in interactions between plants and microbial pathogens. Ann. Rev. Plant Physiol. Plant Mol. Biol. 41:339-367.

Doke, N. 1975. Prevention of the hypersensitive reaction of potato cells to infection with an incompatible race of Phytophthora infestans by constituents of the zoospores. Physiol. Plant Pathol. 7:1-7.

Ferreira, R. B., Monteiro, S., Freitas, R., Santos, C. N., Chen, Z., Batista, L. M., Duarte, J., Borges, A., and Teixeira, A. R. 2006. Fungal pathogens: The battle for plant infection. Crit. Rev. Plant Sci. 25:505-524.

Friesen, T. L., Faris, J. D., Solomon, P. S., and Oliver, R. P. 2008. Hostspecific toxins: Effectors of necrotrophic pathogenicity. Cell. Micribiol. 10:1421-1428.

Fujita, K., Arase, S., Hiratsuka, H., Honda, Y., and Nozu, M. 1994. The role of toxin(s) produced by germinating spores of Pyricularia oryzae in pathogenesis. J. Phytopathol. 142:245-252.

Fujita, K., Arase, S., Honda, Y., and Nozu, M. 1995. Studies on host-selective infection mechanism of Magnaporthe grisea (Hebert) Barr (9): Possibility of phytotoxicity-nondependent induction of susceptibility by susceptibility-inducing factor(s). Ann. Phytopathol. Soc. Jpn. 61:194196.

Gilbert, R. D., Johnson, A. M., and Dean, R. A. 1996. Chemical signals responsible for appressorium formation in the rice blast fungus Magnaporthe grisea. Physiol. Mol. Plant Pathol. 48:335-346.

Heath, M. C., Valent, B., Howard, R. J., and Chumley, F. G. 1990. Interactions of two strains of Magnaporthe grisea within rice, goosegrass, and weeping lovegrass. Can. J. Bot. 68:1627-1637.

Heath, M. C., Howard, R. J., Valent, B., and Chumley, F. G. 1992. Ultrastructural interactions of one strain of Magnaporthe grisea with goosegrass and weeping lovegrass. Can. J. Bot. 70:779-787.

Howard, R. J., Ferrari, M. A., Roach, D. H., and Money, N. P. 1991. Penetration of hard substrates by a fungus employing enormous turgor pressures. Proc. Natl. Acad. Sci. U.S.A. 88:11281-11284.

Iwasaki, S., Nozoe, S., Okuda, S., Sato, Z., and Kozaka, T. 1969. Isolation and structural elucidation of a phytotoxic substance produced by Pyricularia oryzae Cavara. Tetrahedron Lett. 45:3977-3980.

Iwasaki, S., Muro, H., Nozoe, S., Okuda, S., and Sato, Z. 1972. Isolation of 3:4-dihydro-3:4:8-trihydroxy-1 (2H)-naphtalene and tenuazonic acid from Pyricularia oryzae Cavara. Tetrahedron Lett. 1:13-16.
Jiang, C.-J., Shimono, M., Sugano, S., Kojima, M., Yazawa, K., Yoshida, R., Inoue, H., Hayashi, N., Sakakibara, H., and Takatsuji, H. 2010. Abscisic acid interacts antagonistically with salicylic acid signaling pathway in rice-Magnaporthe grisea interaction. Mol. Plant-Microbe Interact. 23:791-798.

Koga, H. 1994. Hypersensitive death, autofluorescence, and ultrastructural changes in cells of leaf sheaths of susceptible and resistant near-isogenic lines of rice $\left(P i-z^{t}\right)$ in relation of penetration and growth of Pyricularia oryzae. Can. J. Bot. 72:1463-1477.

Koga, H., Dohi, K., and Mori, M. 2004. Abscisic acid and low temperatures suppress the whole plant-specific resistance reaction of rice plants to the infection of Magnaporthe grisea. Physiol. Mol. Plant Pathol. 65:3-9.

Lee, Y.-H., and Dean, R. A. 1993. cAMP regulates infection structure formation in the plant pathogenic fungus Magnaporthe grisea. Plant Cell 5:693-700.

Liu, J., Wang, X., Mitchell, T., Hu, Y., Liu, X., Dai, L., and Wang, G.-L. 2010. Recent progress and understanding of the molecular mechanisms of the rice-Magnaporthe oryzae interaction. Mol. Plant Pathol. 11:419427.

Mauch-Mani, B., and Mauch, F. 2005. The role of abscisic acid in plantpathogen interactions. Curr. Opin. Plant Biol. 8:409-414.

Nukina, M., Sassa, T., Ikeda, M., Umezawa, T., and Tasaki, H. 1981. Pyriculariol, a new phytotoxic metabolite of Pyricularia oryzae Cavara. Agric. Biol. Chem. 45:2161-2162.

Oku, H., Shiraishi, T., and Ouchi, S. 1977. Suppression of induction of phytoalexin, pisatin. Naturwissennshaften 64:643

Qi, M., and Yang, Y. 2002. Quantification of Magnaporthe grisea during infection of rice plants using real-time polymerase chain reaction and northern blot/phosphoimaging analyses. Phytopathol. 92:870-876

Rathour, R., Singh, B. M., and Plaha, P. 2002. Host species-specific protoplast damaging activity of spore germination fluids of the pathogen Magnaporthe grisea. J. Phytopahol. 150:576-578.

Schlaman, H. R. M., Giesel, A. A., Quaedvlieg, N. E. M., Bloemberg, G. V., Lugtenberg, B. J. J., Kijne, J. W., Potrykus, I., Spaink, H. P., and Sautter, C. 1997. Chitin oligosaccharides can induce cortical cell division in roots of Vicia sativa when delivered by ballistic microtargeting. Development 124:4887-4895.

Shimizu, T., Jikumaru, Y., Okada A., Okada, K., Koga, J., Umemura, K., Minami, E., Shibuya, N., Hasegawa, M., Kodama, O., Nojiri, H., and Yamane, H. 2008. Effects of a bile acid elicitor, cholic acid, on the biosynthesis of diterpenoid phytoalexins in suspension-cultured rice cells. Phytochem. 69:973-981.

Shiraishi, T., Saito, K., Kim, H. M., Kato, T., Tahara, M., Oku, H., Yamada, T., and Ichinose, Y. 1992. Two suppressors, Supprescin A and B, secreted by a pea pathogen, Mycosphaerella pinodes. Plant Cell Physiol. 33:663-667.

Shiraishi, T., Yamada, T., Ichinose, Y., Kiba, A., and Toyoda, K. 1997. The role of suppressors in determining host-parasite specificities in plant cells. Int. Rev. Cytol. 172:55-93.

Smit, G., de Koster, C. C., Schripsema, J., Spaink, H. P., van Brussel, A. A., and Kijne, J. W. 1995. Uridine, a cell division factor in pea roots. Plant Mol. Biol. 29:869-873.

Talbot, N. J. 2003. On the trail of a cereal killer: Exploring the biology of Magnaporthe grisea. Annu. Rev. Microbiol. 57:177-202.

Tamimi, S. M. 2003. Stimulation of adventitious root formation in nonwoody stem cuttings by uridine. Plant Growth Regul. 40:257-260.

Tanabe, S., Okada, M., Jikumaru, Y., Yamane, H., Kaku, H., Shibuya, N., and Minami, E. 2006. Induction of resistance against rice blast fungus in rice plant treated with a potent elicitor, $N$-acetylchitooligosaccharide. Biosci. Biotechnol. Biochem. 70:1599-1605.

Tanabe, S., Hayashi, N., Nishizawa, Y., Yamane, H., Shibuya, N., and Minami, E. 2008. Elicitor and catalase activity of conidia suspensions of various strains of Magnaporthe grisea in suspension-cultured cells of rice. Biosci. Biotechnol. Biochem. 72:889-892.

Tanabe, S., Nishizawa, Y., and Minami, E. 2009. Effects of catalase on the accumulation of $\mathrm{H}_{2} \mathrm{O}_{2}$ in rice cells inoculated with rice blast fungus, Magnaporthe oryzae. Physiol. Plant 137:148-154.

Tucker, S. L., and Talbot, N. J. 2001. Surface attachment and pre-penetration stage development by plant pathogenic fungi. Anuu. Rev. Phytopathol. 39:385-417.

Umetsu, N., Kaji, J., and Tamari, K. 1972. Investigation of the toxin production by several blast fungus strains and isolation of tenuazonic acid as a novel toxin. Agr. Biol. Chem. 36:859-866.

Wada, M., Kato, H., Malik, K., Sriprasertsak, P., Ichinose, Y., Shiraishi, T., and Yamada, T. 1994. A Supprescin from a phytopathogenic fungus deactivates transcription of a plant defense gene encoding phenylalanine ammonia-lyase. J. Mol. Biol. 249:513-519.

Wolpert, T. J., Dunkle, L. D., and Ciuffetti, L. M. 2002. Host-selective toxins and avirulence determinants: What's in a name? Annu. Rev. Phyto- 
pathol. 40:251-285.

Xiao, J. Z., Ohshima, A., Watanabe, T., Kamakura, T., and Yamaguchi, I. 1994. Studies on cellular differentiation of Magnaporthe grisea. Physicochemical aspects of substratum surfaces in relation to appressorium formation. Physiol. Mol. Plant Pathol. 44:227-336.

Yoshimoto, K., Jikumaru, Y., Kamiya, Y., Kusano, M., Consonni, C., Panstruga, R., Ohsumi, Y., and Shirasu, K. 2009. Autophagy negatively regulates cell death by controlling NPR1-dependent salicylic acid signaling during senescence and the innate immune response in Arabidopsis. Plant Cell 21:2914-2927.

Zellerhoff, N., Jarosch, B., Groenewald, J. Z., Crous, P. W., and Schaffrath, U. 2006. Nonhost resistance of barley is successfully manifested against
Magnaporthe grisea and a closely related Pennisetum-infecting lineage but is overcome by Magnaporthe oryzae. Mol. Plant-Microbe Interact. 19:1014-1022.

Ziegler, E., and Pontzen, R. 1982. Specific inhibition of glucan-elicited glyceollin accumulation in soybean by an extracellular mannan-glycoprotein of Phytophthora megasperma f. sp. glycinea. Physiol. Plant Pathol. 20:321-331.

\section{AUTHOR-RECOMMENDED INTERNET RESOURCE}

National Center for Biotechnology Information Gene Expression Omnibus website: www.ncbi.nlm.nih.gov/geo 